\title{
The influence of individual characteristics on getting involved in an entrepreneurial team: The contingent role of individualism
}

\author{
Nathaly Pinzón ${ }^{1}$ · Javier Montero ${ }^{2}$ - José L. González-Pernía ${ }^{1}$
}

Accepted: 8 September 2021 / Published online: 25 September 2021

(c) The Author(s) 2021

\begin{abstract}
A traditional stereotype of the entrepreneur is that of a lone hero. However, many entrepreneurs engage in new businesses as members of entrepreneurial teams. These teams usually perform better in terms of employment generation, innovation, and profits. Thus, a relevant question is why some individuals get involved in entrepreneurship through a team rather than alone. Our explanation is focused on two variables related to the entrepreneur's human capital: their educational level and their intrapreneurial experience. There are conflicting arguments on how these variables lead an entrepreneur to join a team, and we argue that the degree of individualism of the society helps us understand the discrepancies. We use a sample of 66,716 earlystage entrepreneurs from 66 countries surveyed by the Global Entrepreneurship Monitor between 2014 and 2017. Our results show that entrepreneurs with higher levels of education and intrapreneurial experience are more likely to be involved in the entrepreneurship process as members of teams. However, the effect of educational level is less pronounced in individualist contexts. In addition, we find that the motivation to enter entrepreneurship partially mediates these relationships, as individuals endowed with higher human capital are likely to enter entrepreneurship driven by an opportunistic motivation, which in turns makes them likely to need or join teams to reach their goals.
\end{abstract}

Keywords Entrepreneurial teams · Educational level · Intrapreneurial experience · Opportunity entrepreneurs $\cdot$ Individualism $\cdot$ GEM

Javier Montero

montero@unizar.es

Nathaly Pinzón

nathalypinzon@opendeusto.es

José L. González-Pernía

gonzalez-pernia@deusto.es

1 Deusto Business School, University of Deusto, San Sebastián, Spain

2 Department of Management, University of Zaragoza, Zaragoza, Spain 


\section{Introduction}

One of the typical myths of entrepreneurship has been the notion of the entrepreneur as a lone hero (Cooney, 2005), fighting against competitors and other environmental forces to achieve success. However, many entrepreneurs engage in the early stages of new businesses by joining with partners to make their dreams become a reality. Rather than being established by individuals, new ventures are often the result of entrepreneurial teams (Carland et al., 1984; Cooney, 2005; Lazar et al., 2020). Indeed, some of the most successful entrepreneurs in the world built their businesses in teams. Larry Page and Sergey Brin created Google, Bill Gates and Paul Allen started Microsoft, and Steve Jobs and Steve Wozniak founded Apple, among many other examples. Wasserman (2012) highlighted that 85 percent of high-technology startups were created by entrepreneurial teams with at least two members.

In recent decades, entrepreneurship researchers have studied entrepreneurial teams, defining them as a set of "individuals who have a significant financial interest and participate actively in the development of the enterprise" (Cooney, 2005, p. 229). Therefore, members of an entrepreneurial team have two main characteristics: (1) they have a significant financial interest, so they should have an important share of the ownership; and (2) they manage the company from day to day. Several studies have noted that businesses created by entrepreneurial teams are more likely to survive and experience faster growth rates (Harper, 2008), as well as performing better in terms of employment generation, innovation, and profits (Chowdhury, 2005; Reynolds, 2011; Shane, 2009), than businesses created by solo entrepreneurs. All these elements are key factors in the successful development of a new venture. Consequently, being a member of an entrepreneurial team rather than an individual entrepreneur is an important choice.

Even though being a partner in an entrepreneurial team has several advantages, many individuals still prefer to develop enterprises by themselves. The literature on entrepreneurial teams addresses questions such as why, how, when, and where entrepreneurial teams are formed (Lazar et al., 2020). In particular, previous research has tried to answer questions such as: Why are individuals involved in an entrepreneurial team? How are cofounders selected? Where do members of a team look for potential partners? In the present study, we attempt to explain why individuals are involved in a new venture with partners rather than on their own, and the factors that play a role in the process. Shane and Venkataraman (2000) describe entrepreneurship research as "the study of sources of opportunities; the processes of discovery, evaluation, and exploitation of opportunities; and the set of individuals who discover, evaluate, and exploit them" (p. 218). In the present study, the importance of the entrepreneur's individual characteristics is highlighted. These characteristics have proven to be useful in explaining why individuals are involved in business creation. Previous researchers have highlighted the importance of individuals' educational level and their intrapreneurial experience as factors that explain the predisposition of individuals to be involved in entrepreneurial teams, but the findings have been inconsistent.

For example, previous studies have shown that individuals with a higher level of education are more aware of their weaknesses and therefore seek out people 
who complement their abilities, skills, and knowledge (Chowdhury, 2005). The higher the educational level of the entrepreneur, the greater the likelihood that they will be part of an entrepreneurial team. Other research has suggested that highly educated individuals are more autonomous and are more confident in their own skills and capabilities (Davidsson \& Honig, 2003), so they prefer to have complete control of their business and want to manage a new venture alone. With regard to the intrapreneurial experience, we also find conflicting results. On the one hand, previous research has argued that individuals with previous intrapreneurial experience are used to working as a part of a team within an organization, and they know how to manage team interactions to extract the members' full potential (Guth \& Ginsberg, 1990). For this reason, it has been suggested that intrapreneurial experience increases the likelihood of being part of a team. On the other hand, other research has stressed that ventures promoting intrapreneurship foster employees' autonomy (Bosma et al., 2010), so individuals with intrapreneurial experience prefer to manage new ventures on their own (Hayton, 2005).

Shane and Venkataraman (2000) emphasize that it is not possible to take individuals into account without considering the contexts in which they are operating. Indeed, Lazar et al. (2020) demonstrate that one fertile area of research is the analysis of how contextual factors shape the formation of teams. One of the most important dimensions of context is the culture of a country (Autio et al., 2013; Busenitz \& Lau, 1996). Hofstede (1984) defines culture as "the collective programming of the mind which distinguishes the members of one human group from another... [and] includes systems of values" (p. 21). As an underlying system of values, culture shapes the development of certain personality traits and motivates individuals in a society to engage in behaviors that may not be as prevalent in other societies (Donaldson, 2021; Mueller $\&$ Thomas, 2001). One dimension of culture that may be particularly relevant in the creation of teams is the degree of individualism in a society. This is considered to be a key element in describing people's behaviors and attitudes (Li \& Zahra, 2012), and should be understood as a continuum in which individualism and collectivism are at opposite ends of the spectrum (Hofstede, 2001). We focus on this dimension because it expresses the cultural tendency to place more value on the individual or group (Hofstede, 1984), and we believe that it will help to reconcile the conflicting results in previous literature.

Furthermore, we have to be aware that the individual characteristics analyzed (educational level and intrapreneurship experience) may influence the motivation to create a new business (opportunity vs necessity entrepreneurship), which can, in turn, influence the value added of entrepreneurs' businesses and their predisposition to look for partners instead of managing a new business alone. Looking at this mediating mechanism may help to explain why (and not only in what circumstances) entrepreneurs look for partners.

The objective of the present study is to deepen our understanding of how certain individual attributes of entrepreneurs influence the likelihood of getting involved in an entrepreneurial team (instead of managing a new venture alone), and how the degree of individualism of the society moderates such an influence. The study is relevant because entrepreneurial teams are much more frequently found in new venture creation than might be expected given the evidence presented in the entrepreneurship 
literature, and they strongly shape new ventures' performance (Cooney, 2005; Klotz et al., 2014).

The present study makes three main contributions to the literature. Firstly, it provides a multilevel approach to the influence of individual characteristics (in particular, educational level and intrapreneurial experience) on the decision to be part of an entrepreneurial team. More importantly, it shows that the effect of these factors is moderated by the level of individualism in a society. This cultural dimension explains why individuals with similar educational levels and intrapreneurial experience make different decisions concerning the creation of an entrepreneurial team in different cultural contexts. Secondly, the study reveals that opportunity motivation partially mediates the relationship between individual factors and involvement in an entrepreneurial team. In particular, we argue that individuals with a high educational level and intrapreneurial experience are more likely to be motivated by a business opportunity, more often getting involved in a team. Thirdly, to the best of our knowledge, the study is the first to analyze across countries the empirical relationship between certain characteristics of individuals and their propensity to become involved in entrepreneurial teams. The wide range of countries in the sample and the time horizon selected allow the possibility of generalizing our results.

\section{Theoretical framework and hypotheses}

In recent decades, the literature on team formation has addressed issues such as: (1) why entrepreneurial teams are formed; (2) how cofounders are selected; (3) where founders look for potential partners; and (4) what kind of factors stimulate individuals to look for partners when they create a new venture (Lazar et al., 2020). The main goal of the present study is to analyze why some individuals prefer and decide to be involved in a new venture with partners instead of doing it by themselves. The objective of our research is related to some of the previous research questions, so we are going to review how the literature has tried to answer them. If we are wondering why some individuals prefer to be involved in a new venture with partners, we should also try to find out why teams are formed, how and where cofounders are selected, and which individual attributes lead to the decision to share the leadership of new business projects.

The previous literature has addressed the issue of why entrepreneurial teams are formed in two main ways. The first argues that one individual has a business idea and then looks for partners to develop their project. In this situation, the idea comes before the team (see, for example, Grossman et al., 2012; Kamm et al., 1990). The second stream explains how a group of founders takes the decision to start a project and they develop the idea together; that is, the team comes before the idea (see, for example, Kamm \& Nurick, 1993). Both explanations are possible, because the formation of an entrepreneurial team may be useful not only for the exploitation of a business opportunity but also for its identification. For this reason, in our research we do not differentiate between the two possibilities, focusing only on the fact that some individuals are involved in entrepreneurial teams while others prefer to manage their new venture alone. 
Another interesting issue is how cofounders are selected, and it is here that the previous literature has proposed a range of explanations (Lazar et al., 2020). One of these is the interpersonal attraction strategy. Cofounders select each other because they share similar interests and possess perceived admirable qualities. In that sense, cofounding relations arise because of the need to work with similar individuals with whom one can initiate a rich and fruitful connection (Lazar et al., 2020). Another strategy is the resource-seeking strategy, in which cofounders are selected based on the resources that are required for the creation of the new venture. This strategy highlights the complementarity among members. It is focused on individuals' human capital (i.e., knowledge, skills, and capabilities), which allows access to relevant resources and assets.

The third issue is where founders look for potential partners. This is closely related to the second question. The previous literature has revealed the role played by networks. Individuals are much more likely to find potential partners among people they already know. Studies have highlighted the role played by the educational process and previous employment (Kacperczyk, 2012; Kacperczyk \& Marx, 2016). As a result, the educational level and the intrapreneurial experience of the individual are two fertile contexts in which to find the right partners for the creation of an entrepreneurial team.

Finally, what kind of factors stimulate individuals to look for partners? Previous research has studied many of these. Two are particularly relevant-the educational level of individuals and their intrapreneurial experience (Davidsson \& Honig, 2003; Mindruta, 2013; Wasserman, 2012)_but the arguments have been inconsistent. As we have explained above, one way of advancing our understanding of this subject is to take into account the context in which individuals operate (Donaldson, 2021), and to examine whether their behavior is contingent on that context. Our analysis is focused on the moderating role of individualism. We think that this dimension is closely related to why some individuals enter into entrepreneurship alone and others prefer to do so with partners, and so is closely related to the present study's objectives. Furthermore, as we have highlighted, we cannot ignore that individuals' attributes strongly affect motivation. In particular, both educational level and intrapreneurial experience may affect the pursuit of a business opportunity, which is turn positively affects the desire to be involved in a team. Looking at this mediating mechanism helps to explain why entrepreneurs look for partners.

Our theoretical model is summarized in Fig. 1. We propose two direct relationships between individual factors (educational level and intrapreneurial experience) and the likelihood of being a member of an entrepreneurial team (hypotheses 1 and 2 ). The previous literature has presented conflicting arguments on these relationships. The level of individualism will help us to reconcile these conflicting results, because we understand that the influence of individual factors is not the same in countries with different cultural profiles. For this reason, we propose two additional moderating relationships (hypotheses $4 \mathrm{a}$ and $4 \mathrm{~b}$ ). Finally, we introduce the motivation of the entrepreneur as a factor that mediates the relationship between individual characteristics and involvement in a team, establishing a mediating relationship (hypothesis 3). In the three next subsections, we develop this framework. 


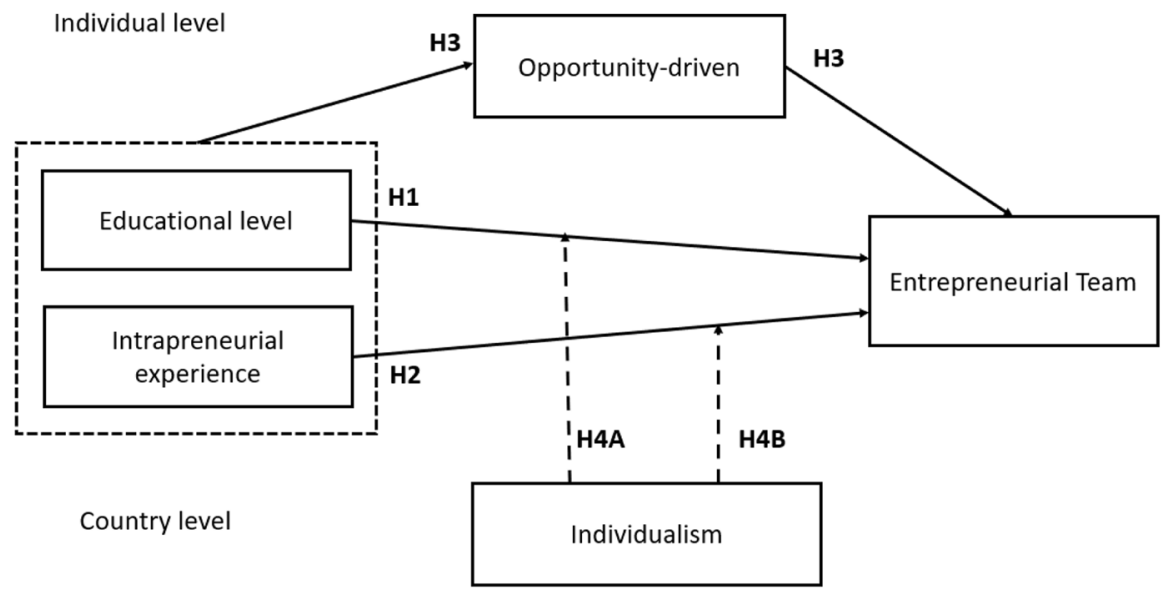

Fig. 1 Conceptual framework

\section{Individuals' characteristics and involvement in entrepreneurial teams}

In this section, we analyze the influence of individuals' educational level and intrapreneurial experience on the likelihood of being involved in a team.

\section{Educational level}

Opportunity discovery is not easy. Some scholars have argued that it depends on the previous information that individuals have (Kato et al., 2015). The ability to create and recognize market opportunities requires a set of basic tools and knowledge, suggesting that systematic training may be necessary (Shane, 2000), at least in the case of high value-added openings. Therefore, the educational level of the entrepreneur plays a key role. We can confirm that entrepreneurs with higher levels of education have a more specific skillset because they are specialists in particular disciplines (for instance, management, law, science, or engineering). For this reason, they do not always possess all the specific abilities and capabilities needed to start a new venture on the basis of an idea (Kamm \& Nurick, 1993; Wasserman, 2012), so they need to find people who have similar beliefs and interests, and particular abilities and competencies that complement their individual human capital (Aldrich \& Kim, 2007; Mindruta, 2013). Moreover, previous research has indicated that individuals with higher levels of education are capable of identifying their own weaknesses and looking for partners who can compensate for these (Chowdhury, 2005). Therefore, following the resource-seeking strategy, in which entrepreneurs are selected based on the resources required for a new venture, individuals of a higher educational level may be more likely to be involved in a business as a member of a team.

However, some researchers have suggested that the opposite may be the case. Individuals with a high educational level may also be more prepared to set up a new 
venture because they have more skills and knowledge; so, following the resourceseeking strategy, this may reduce the likelihood of being involved in a team. Furthermore, highly educated individuals are more autonomous and confident in their own skills and capabilities (Davidsson \& Honig, 2003). For this reason, they may prefer to have control over their project and think that developing a new venture alone may be a better option.

Nevertheless, we have to consider that the educational process enhances individuals' networks of contacts, which improves the likelihood of them finding the right partners (Wennberg et al., 2011). It seems reasonable to suggest that this network will be smaller among individuals with a lower level of education. The more an individual accomplishes in formal studies, the wider their network will be, and the higher the probability of them creating teams (Huang et al., 2013; Yusuf, 2012). Previous research has found that most of the partnerships in a new venture arise from friendships between individuals. This kind of argument is based on the interpersonal attraction strategy (Lazar et al., 2020). Recognizing that our reasoning may offer arguments in both directions, we believe that individuals with higher levels of education are, on average, more aware of their limitations and have a larger network of contacts that will allow them to find the right partners. We therefore propose the following hypothesis:

Hypothesis 1: A higher educational level increases the likelihood of the entrepreneur of being involved in a business as a member of a team (instead of alone).

\section{Intrapreneurial experience}

Intrapreneurial experience is the output of a learning-by-doing process, where employees develop intrapreneurial activities within an organization and acquire specific knowledge and leadership skills (Guerrero \& Peña-Legazkue, 2013). Companies support intrapreneurs with finance and access to corporate resources, while intrapreneurs create innovation for companies, developing new ideas with work partners (Covin \& Miles, 1999). Entrepreneurs with intrapreneurial experience discover the advantages and disadvantages of working as part of a team, and they know how to manage team interactions to enable effective communication and to resolve conflict among members (Guth \& Ginsberg, 1990). As a result, they can strengthen the pros and manage the cons of working as part of a team. Some studies have stressed that ventures which promote intrapreneurship foster employees' autonomy (Bosma et al., 2010; Fis \& Cetindamar, 2021) because they want those involved to develop their own projects, without taking into account the main business objectives of the company. This argument leads us to think that individuals with intrapreneurial experience would prefer to create a new venture alone (Hayton, 2005). They have good skills, so following the resource-seeking strategy, they do not need partners to pursue market opportunities.

Nevertheless, most of the intrapreneurship literature acknowledges that intrapreneurs develop the capability of working in an interdisciplinary way, because intrapreneurial projects within organizations often require close attention to complex 
financial, technical, and administrative issues, including collecting, analyzing, and interpreting data from internal and external environments. This kind of argument is in keeping with the resource-seeking strategy. Moreover, intrapreneurs know that by facilitating integration between organizational units, they enable a more fluid exchange of information, which ultimately benefits the success of projects. Companies that promote intrapreneurship invest more time and effort in group-oriented training, which supports cooperation and knowledge sharing (Hayton, 2005). Consequently, intrapreneurial experience provides entrepreneurs with a means of developing projects based on cooperation and integration.

Finally, intrapreneurial experience provides entrepreneurs with the opportunity to find suitable people for their teams because they have a broader network of contacts. Many entrepreneurs keep in close touch with their former employees and coworkers, who then become a key part of their networks (Aldrich \& Kim, 2007; Kamm $\&$ Nurick, 1993). Following the interpersonal attraction strategy, previous intrapreneurs can subsequently find partners for their new venture more easily. We therefore propose the following hypothesis:

Hypothesis 2: Intrapreneurial experience increases the likelihood of the entrepreneur of being involved in a business as a member of a team (instead of alone).

\section{The mediating effect of entrepreneurial motivation}

Both educational level and intrapreneurial experience strongly influence the motivation to create a business, and this also affects the likelihood of an individual being involved in a venture as part of a team. Some individuals enter into entrepreneurship looking for flexibility in their work schedules; others are pursuing their passion and dreams; and others see entrepreneurship simply as a way to earn a living. Reynolds et al. (2005) distinguish between opportunity and necessity entrepreneurs. Opportunity entrepreneurs identify possible business openings, while necessity entrepreneurs start new ventures because of a lack of better job prospects. The entrepreneurship literature has explained that opportunity-driven and necessity-driven entrepreneurs differ systematically in their expectations of job creation, their export revenues, and their innovation levels (Reynolds et al., 2005).

Entrepreneurs with higher levels of education are more likely to be involved in the entrepreneurial process by opportunity, because these individuals are attractive on the job market and so are less likely to be pushed into entrepreneurship by necessity (Arenius \& De Clercq, 2005). Therefore, people characterized by higher levels of human capital (higher levels of education or intrapreneurial experience) are likely to become entrepreneurs only if they can act upon value-creating opportunities. In contrast, entrepreneurs with a lower educational level generally pursue lower valueadded and less sophisticated opportunities, so they do not have such a great need for the resources and knowledge of other individuals. For them, creating a new venture is a matter of necessity (Fuentelsaz et al., 2015). Therefore, the educational level of the entrepreneur has a positive influence on whether they are an opportunity entrepreneur. Similarly, individuals with previous intrapreneurial experience generally 
have a better experience background because they will have held a job in an enterprise for a long time, and this will have allowed them to pursue projects with greater freedom. It seems reasonable to think that, if they decide to create a new venture, it will be motivated by the discovery of a business opportunity (Turró et al., 2016), and not because they do not have better job options. Therefore, both individual factors make it more likely that these individuals are opportunity-driven entrepreneurs. Nevertheless, to develop their business idea successfully, a team may be very important (Grossman et al., 2012; Kamm et al., 1990).

Previous research has also shown that a good business idea requires different types of knowledge and skills. Transforming an idea into a real project requires entrepreneurs to establish links with others who control resources or have resource connections (Aldrich \& Kim, 2007). For this reason, opportunity-driven entrepreneurs look for people with different characteristics and experience to enhance the likelihood of achieving their own ambitions and goals (Tabares et al., 2021). Opportunity entrepreneurs attempt to manage growth successfully by finding people for their teams (Aldrich \& Kim, 2007; Klotz et al., 2014; Ruef, 2010). In contrast, necessity-driven entrepreneurs often spend less time designing their ventures, making the business less attractive to other potential team candidates.

Opportunity-driven entrepreneurs will often create and develop projects involving challenging tasks that require specific and diverse knowledge (Tabares et al., 2021). The entrepreneurs need a broad range of resources (Cullen et al., 2014), leading them to seek support from other people with better resources and capabilities. These entrepreneurs follow the resource-seeking strategy, looking for other people, who are selected based on the resources required for the new venture. In the same way, involvement in an entrepreneurial team helps identify better business opportunities. We therefore propose the following hypothesis:

Hypothesis 3: Being an opportunity-driven entrepreneur mediates the relationship between individual characteristics (i.e., educational level and intrapreneurial experience) and the likelihood of being involved in a business as a member of a team (instead of alone).

\section{The contingent role of individualism}

In hypotheses 1 and 2, we have established different relationships among certain individual entrepreneurial characteristics and the likelihood of being involved in a team. However, entrepreneurs are influenced by the institutional context in which they operate (Autio \& Acs, 2010). Culture is one of the main contextual elements influencing entrepreneurial behavior. The degree of individualism of a country is a cultural dimension that can help us to explain the conflicting arguments in the previous literature.

As we have explained above, individualism and collectivism are the opposite poles of a continuum (Hofstede, 2001). In individualist societies, individuals are expected to take care only of themselves and their immediate families. These are societies where people are motivated by individual rewards. In collectivist countries, individuals are considered from birth to be part of a group, and they are more 
oriented to collectivist rewards (Triandis, 1993). Traditionally, individualism has been related to entrepreneurship, because many of the characteristics of entrepreneurs seem to refer to an individualist orientation, such as autonomy, independence, the need for control, and self-confidence (Taylor \& Wilson, 2012).

In hypothesis 1 , we have argued that entrepreneurs with higher levels of education have a very specific knowledge of some subjects but they may need other resources to complement their knowledge. Similarly, the educational process is an important source of contacts, providing a wide range of options by which find the right partners. However, highly educated individuals are also more autonomous and are more confident in their own capabilities, and so are less likely to look for business partners.

In an individualist society, a high educational level gives entrepreneurs a set of skills and abilities that incentivize the creation of a lone venture, because they may believe that they have the requisite knowledge. Moreover, although they are capable of identifying their weaknesses, the entrepreneurs may prefer to have total control over their business and to involve new people as employees or external collaborators. They have a lower appreciation of cooperative strategies, and they prefer to be more independent to make their own decisions without taking others' opinions into account (Steensma et al., 2000). In contrast, in less individualist societies, individuals are more likely to collaborate in order to identify and concretize an opportunity rather than relying solely on the human capital acquired through the education process. In this sense, if entrepreneurs do not have all the necessary resources, they will not feel inconvenienced by having to incorporate new partners. In this kind of society, group decisions are considered better than individual decisions. As a consequence, individual initiatives are discouraged (Hayton et al., 2002; Thomas \& Mueller, 2000), and entrepreneurs with a high level of education have a greater incentive to involve other partners.

Hypothesis 4a: The positive relationship between educational level and the entrepreneurial team is negatively moderated by individualism.

We have proposed in hypothesis 2 that entrepreneurs with intrapreneurial experience have better knowledge of the advantages and disadvantages of working as a part of a team. In addition, the intrapreneurial experience may be very important for identifying the right partners for their new business. However, it is also true that ventures that promote intrapreneurship also foster employees' autonomy, so individuals with intrapreneurial experience might prefer to create a new venture alone.

Nevertheless, in individualist countries, the intrapreneurial process is based on individual competition, instigating a stronger employee self-concept and more selfconfidence (Morris et al., 2006). For this reason, individuals are focused on individual rewards, being less used to working as a part of the team; such entrepreneurs will therefore prefer to work alone. If they need additional resources, then they will look for specialized individuals or workers, but without involving them as members of the team (i.e., without having a significant financial interest in the venture). In contrast, entrepreneurs with intrapreneurial experience in less individualist societies well know the benefits of working as part of a team and will therefore prefer to develop their business with partners, especially if this is necessary to have a high 
value-added business. These individuals will be more likely to collaborate with others to identify and exploit a business opportunity. They will then prefer to integrate people into teams. We therefore propose the following hypothesis:

Hypothesis 4b : The positive relationship between intrapreneurial experience and an entrepreneurial team is negatively moderated by individualism.

\section{Methodology}

\section{Empirical model}

We aimed to assess the effects of the entrepreneur's educational level and intrapreneurial experience on the likelihood of being member of a team rather than a solo entrepreneur at the individual level (hypotheses 1 and 2). We formulated that these effects were mediated by the motivation of the entrepreneur to start their businessthat is, whether it was opportunity-driven or not (hypothesis 3). In addition, we proposed that these effects at the individual level were contingent on the role of individualism at the country level (hypotheses $4 \mathrm{a}$ and $4 \mathrm{~b}$ ). To estimate this moderated mediation model with the predictors, mediator and outcome measured at level 1 , and the moderator measured at level 2, we used a multilevel logistic regression analysis under a path-analytic framework with the aid of modern statistical computing tools (Imai et al., 2010; Tingley et al., 2014) to quantify and probe both conditional (i.e., moderation) and indirect (i.e., mediation) effects. The model required the estimation of two systems of equations, one for the mediator and one for the dependent variable (Hayes, 2018), to compute the coefficients for each of the paths depicted in Fig. 2.

The first system of equation regresses the mediator variable on the explanatory variables, as follows:

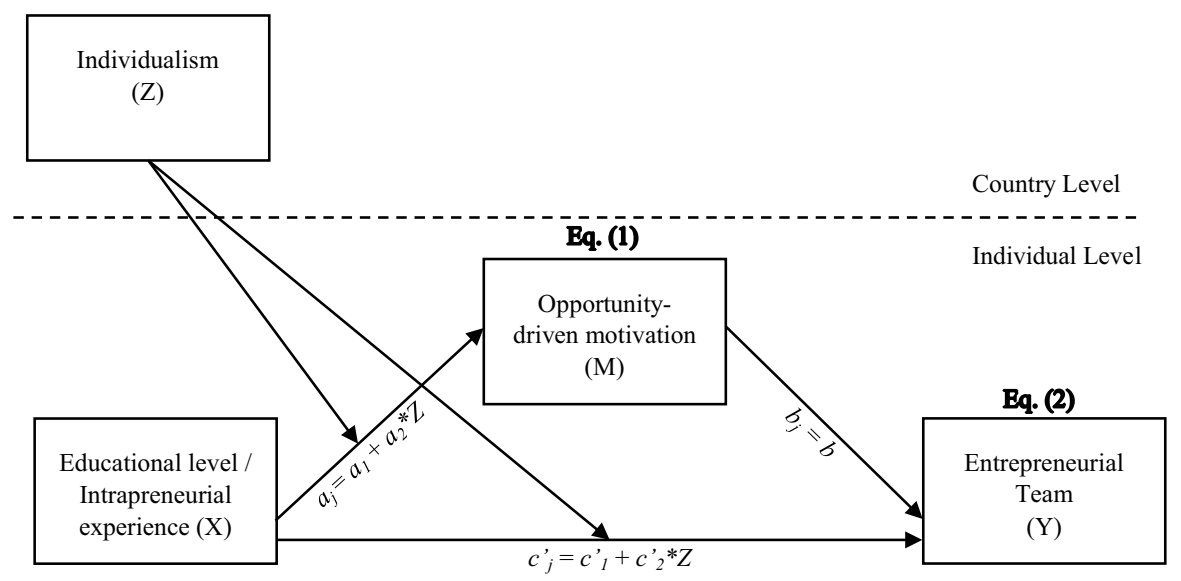

Fig. 2 Graphic representation of multilevel moderated mediation model and estimation of each path 


$$
\begin{gathered}
\text { Level } 1: M_{i j}^{*}=B_{1 j}+a_{j} X_{i j} \\
\text { Level } 2: B_{1 j}=\gamma_{10}+\gamma_{11} Z_{j}+u_{1 j} \\
a_{j}=a_{1}+a_{2} Z_{j}+u_{a j}
\end{gathered}
$$

where $M_{i j}^{*}$ is the $\log$ odds that the early-stage entrepreneur $i$ in country $j$ reports opportunity as the major motive to start their business; $\mathrm{X}_{i j}$ is the vector of individual-specific explanatory variables measured at level 1 ; and $Z_{j}$ is the country-specific moderator variable measured at level 2 . The level 1 coefficients are modeled as a function of level 2 country-specific components. Thus, the coefficient $\beta_{1 j}$ represents the intercept for country $j$, which is the sum of a fixed effect, $\gamma_{10}$, and a random effect, $u_{1 j}$, controlling for the fixed main effect of the moderator, $\gamma_{11}$. The coefficient $a_{j}$ represents the path of the effect of each explanatory variable on the mediator for country $j$ (see Fig. 2), which is composed of a fixed main effect, $a_{1}$; a fixed crosslevel interaction effect, $a_{3}$; and a random effect, $u_{a j}$, that captures the variability in the slopes across countries $j$.

The second system of equation regresses the dependent variable on the explanatory variables and the mediator, as follows:

$$
\begin{gathered}
\text { Level } 1: Y_{i j}^{*}=B_{2 j}+c_{j}^{\prime} X_{i j}+b_{j} M_{i j} \\
\text { Level } 2: B_{2 j}=\gamma_{20}+\gamma_{21} Z_{j}+u_{2 j} \\
c=c_{j}^{\prime}+c_{2}^{\prime} Z_{j}+u_{c j} \\
b_{j}=b
\end{gathered}
$$

where $Y_{i j}^{*}$ is the log odds that the early-stage entrepreneur $i$ in country $j$ is involved in a nascent or new business as member of a team; $X_{i j}$ is again the set of individualspecific explanatory variables measured at level $1 ; M_{i j}$ is the individual-specific mediator measured at level 1 ; and $\mathrm{Z}_{j}$ is the country-specific moderator variable measured at level 2 . The coefficient $\beta_{2 j}$ is the intercept for country $j$, modeled as a function of a fixed effect, $\gamma_{20}$, the fixed main effect of the moderator, $\gamma_{21}$, and a random effect, $u_{2 j}$. The coefficient $c_{j}^{\prime}$ represents the path of the direct effect of each explanatory variable on the dependent variable for country $j$ (see Fig. 2), which is the sum of a fixed main effect, $c_{1}^{\prime}$; a fixed cross-level interaction effect, $c_{2}^{\prime}$; and a random effect, $u_{c j}$, that captures the variability in the slopes across countries $j$. Finally, the coefficient $b_{j}$ represents the path of the effect of the mediator on the dependent variable (see Fig. 2), which is composed of a fixed effect only, as we do not expect it to vary across countries $j$.

In a multilevel mediation model, the indirect effect is the product of the fixed effect of the predictor (i.e., educational level and intrapreneurial experience) on the mediator (i.e., opportunity-driven motivation) and the fixed effect of the mediator on the outcome (i.e., entrepreneurial team), plus the covariance between the random effects of both paths (Bauer et al., 2006). Thus, in our model, the unconditional (mediated) indirect effect is defined as $a_{1} * b+\sigma_{a, b}$, where $\sigma_{a, b}$ is the covariance between the random effects. However, as the effect of the mediator on the outcome is fixed across countries $j$ (i.e., $b_{i}=b$ ), then $\sigma_{a, b}=0$, and the mediation effect is reduced to $a_{1} * b$ (Hayes \& Rockwood, 2020). If the direct 
effect is moderated, then it is expected that the indirect effect is also moderated. Accordingly, we estimated the moderated direct effect as $c_{1}^{\prime}+c_{2}^{\prime} Z_{j}$ and the moderated mediation effect as $\left(a_{1}+a_{2} Z_{j}\right) * b$. We empirically quantified and tested these effects using the quasi-Bayesian Monte Carlo method (Imai et al., 2010) implemented in the statistical software provided by Tingley et al. (2014) with 1,000 simulation subsamples. ${ }^{1}$

\section{Sample and data sources}

We combined data at the individual and country levels from several sources. Firstly, at the individual level, we used cross-sectional data on entrepreneurs from the Adult Population Survey (APS) conducted by the Global Entrepreneurship Monitor (GEM) project. Secondly, we used country-level data from Hofstede's national culture model (Hofstede, 2001). Thirdly, additional data on control variables at the country level came from the World Bank's World Development Indicators database (World Bank, 2020) and the Heritage Foundation's Index of Economic Freedom database (Heritage Foundation, 2020). By combining the aforementioned sources, we created a hierarchical dataset with information at the individual and country levels.

We used the GEM project's APS as the main source to build the sample. In each participating country, the GEM project's APS annually surveys a different representative sample of the adult population to identify three types of entrepreneur according to the phase of business creation: nascent, new, and established entrepreneurs. Nascent and new entrepreneurs are usually the focus of analysis in studies on the early stages of the entrepreneurial process, because they actively participate in the start-up phase or the management and ownership of a new business that had paid salaries for less than 42 months (for more details, see Reynolds et al., 2005). Thus, we selected a sample of 66,716 early-stage entrepreneurs (i.e., nascent and new entrepreneurs) identified by the GEM project across 66 countries over the period $2014-2017$.

Gartner et al. (2004) found that the business creation process begins with activities related to team formation in only a few cases (e.g., organizing a team as a first start-up activity was carried out by only 6 percent of a cohort of 822 ventures in the United States). In other words, not all members join entrepreneurial teams simultaneously at their inception (Cooney, 2005). However, entrepreneurial teams are usually formed in the early stages of the business creation process (Klotz et al., 2014; Schjoedt \& Kraus, 2009). Accordingly, we conjectured that including both nascent and new entrepreneurs in the sample would allow us to capture cases during the points at which would-be teams had already been formed, indicating that those who owned and managed new businesses by themselves were truly solo entrepreneurs.

\footnotetext{
1 Bootstrapping is the typical simulation-based method used to construct confidence intervals of direct and indirect effects in modern mediation analysis. However, it is not clear how this method produces confidence intervals across samples of level 1 and level 2 units in a multilevel model. According to Hayes and Rockwood (2020), the estimation of Monte Carlo confidence intervals is an alternative to bootstrapping in multilevel models. Imai et al. (2010) found that 1,000 simulations are sufficient.
} 
Note that, as the unit of analysis is the individual, observations from our sample may be identified as solo entrepreneurs or members of an entrepreneurial team, but only data from the individual respondent are available. In addition, data on each early-stage entrepreneurs identified by the GEM project are collected at a single time point, which means that we cannot unequivocally claim that information on one variable precedes information on other variables in time. However, as Hayes (2018) argues, with cautions and caveats, "one can conduct a mediation analysis even if one cannot unequivocally establish causality given the limitations of one's data collection" (p. 81). Despite these limitations, the richness of the data from the GEM project allows harmonized comparisons across countries, which has made it a key data source for entrepreneurship research (Bosma, 2013).

\section{Variable measurement}

Table 1 summarizes the variables used in the present study. We provide a more detailed description below.

\section{Dependent variable}

Entrepreneurial teams are defined as a group of "two or more individuals who pursue a new business idea, are involved in its subsequent management, and share ownership" (Lazar et al., 2020, p. 29). The GEM project identifies early-stage entrepreneurs as those who actively participate in the start-up phase or in both the ownership and management of the new business (Reynolds et al., 2005). In addition, entrepreneurs identified by the GEM project are asked how many people, including themselves, both own and manage the business. ${ }^{2}$ Thus, if the entrepreneur owned and managed the business on their own, we considered them a solo entrepreneur. In contrast, if they shared the ownership and management of the business with others, we considered them a member of a team. Our dependent variable, Entrepreneurial team, is a binary variable that takes the value one (1) if the entrepreneur is involved in a team, and the value zero (0) if the entrepreneur is involved in a new venture alone. Among those considered a member of a team, this operationalization did not distinguish whether the respondent was a founder or a new member added in the process. However, our interest is to understand why an individual is involved in entrepreneurial activity as a member of a team rather than a solo entrepreneur, regardless of their involvement as founder.

\section{Explanatory variables}

Educational level. This variable comes from the GEM project's APS and captures the highest level of education attained by the respondent entrepreneur. The

\footnotetext{
${ }^{2}$ In the GEM project, entrepreneurs are initially identified as nascent or owner-managers. Depending on the answer, they are respectively asked the following questions: "How many people, including yourself, will both own and manage this new business?" or "How many people both own and manage this business?".
} 


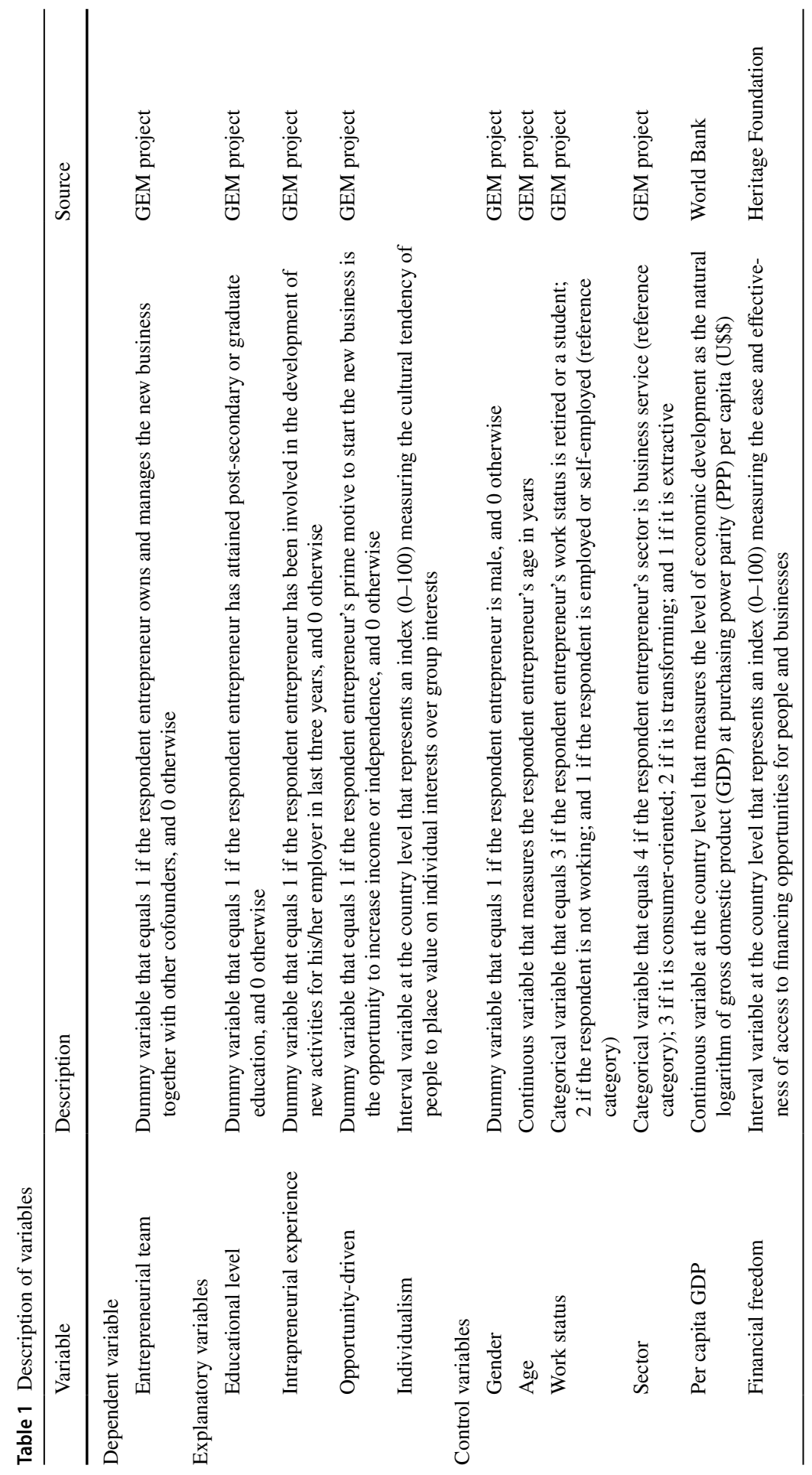


educational process, particularly during post-secondary education or higher stages (i.e., college or graduate studies), increases the chance of developing professional networks and acquiring specific knowledge that benefit from complementarity with others. Therefore, educational level was measured as a binary variable that took the value one (1) if the entrepreneur had undertaken post-secondary level studies, and the value zero (0) if the entrepreneur had no education, pre-secondary and secondary education.

Intrapreneurial experience. Individuals accumulate intrapreneurial experience while working for an existing organization that develops innovative projects in teams (Guerrero \& Peña-Legazkue, 2013). The GEM project's APS asks entrepreneurs whether, in the last three years, they have played a leading role in developing and launching new products or services as an employee or setting up a new business unit or establishment for an organization (Bosma et al., 2010). We used responses to this question as a proxy for intrapreneurial experience, which was measured as a binary variable that took the value one (1) if the entrepreneur had had intrapreneurial experience. Otherwise, it took the value zero (0).

\section{Mediating variable}

Opportunity-driven. There may be as many motives to start a new business as there are individuals involved in entrepreneurial activity. However, the literature has distinguished at least two broad motives, namely, necessity and opportunity (Carsrud et al., 2009; Fuentelsaz et al., 2015; van der Zwan et al., 2016). Under the GEM methodology, necessity-driven entrepreneurs are those who are involved in entrepreneurial activity because they have no better work choices, while opportunity-driven entrepreneurs are those who engage in entrepreneurial activity to take advantage of an opportunity for some form of gain (Reynolds et al., 2005). This variable captured whether the entrepreneur's major motive to become involved in a business was opportunistic, meaning that the main driver was to be independent or to increase income rather than just to maintain an income. Thus, this variable took the value one (1) if the entrepreneur reported opportunity as a major motive to start a business; otherwise, it took the value zero (0).

\section{Moderating variable}

Individualism. In individualist contexts, people consider themselves independent and free to pursue individual interests as opposed to group interests, which is more prevalent in collectivist societies (Hofstede, 1984). To measure the cultural tendency to place value on individual goals, each country was scored using the individualism index from Hofstede's national culture model (Hofstede, 2001), ranging from zero (0) if the country was fully collectivist to one hundred (100) if the country was fully individualist. Because this was a moderator variable, it was mean-centered before the interaction terms were calculated to improve interpretation of the cross-level interaction effect (Aguinis et al., 2013). 


\section{Control variables}

Following previous research, an additional set of variables was included to control for other factors that may have influenced the likelihood of starting a business as a member of a team (Hart, 2014; Held et al., 2018; Ruef et al., 2003; Ucbasaran et al., 2003). Firstly, we controlled for the gender of the respondent entrepreneur, because previous studies have identified this as a driver of team formation (Ruef et al., 2003). The evidence shows that male entrepreneurs are more likely than female entrepreneurs to form entrepreneurial teams (Davis \& Shaver, 2012; Hart, 2014). The variable Gender assigned the values zero (0) and one (1) to female and male entrepreneurs, respectively.

Secondly, we controlled for the age of the respondent entrepreneur. Young entrepreneurs may have less experience, which a priori makes them more likely to join others in the business creation process to complement their own human capital. However, the networks of younger entrepreneurs may be much less developed than those of older entrepreneurs. The scarce empirical evidence in this regard is not conclusive (Ucbasaran et al., 2003). Therefore, the influence of age on the likelihood of starting a business as a member of a team was not clear. The variable Age was measured in number of years. In addition, we added the squared term of Age to test for nonlinear effects.

Thirdly, we controlled for the work status of the respondent entrepreneur. Before getting fully involved in entrepreneurship, a majority of entrepreneurs start their ventures in combination with other occupations due to the advantages that this approach entails, such as leaving time for education, generating additional income from a waged job, gaining knowledge about the market, or reducing the risk (Block \& Landgraf, 2016). In particular, working provides access not only to resources and ideas that are crucial to start a new business (Arenius \& Minniti, 2005), but also to social capital that may aid in finding partners to form teams. The variable Work status was composed of three categories. It took the value one (1) if the entrepreneur was a full- or part-time worker; the value two (2) if the entrepreneur was not working because they were either an employment seeker or a homemaker; and the value three (3) if the entrepreneur was retired or a student. We chose being a full- or part-time worker as the reference category because most entrepreneurs fell into this category.

Fourthly, we controlled for the sector in which the entrepreneur's business operated. The nature of the business activity determines the need for resources, and activities transforming and developing products and knowledge require more resources than service developers and providers (Ruef et al., 2003). In addition, transforming and knowledge-generating activities are more likely to require economies of scale through organizational growth (Audretsch et al., 2004). Accordingly, the greater need for resources and growth may lead entrepreneurs running a transforming business to undertake the entrepreneurship process as members of a team, while those running a consumer-oriented business may go it alone. Similarly, since the knowledge required may be very technical and a single person may not have it all, entrepreneurs are likely to start a business as a team project when they provide business-oriented services (Cooper et al., 1989; Gartner, 1985). Finally, industries 
with high levels of competition increase the need for cofounders (Wasserman, 2012). The variable Sector was measured as categorical and took the value one (1) for extractive activities; the value two (2) for transforming activities; the value three (3) for consumer service activities; and the value four (4) for business service activities. We chose business service activities as the base category because this sector had the highest number of members of entrepreneurial teams.

Fifthly, we controlled for the level of economic development of the country, measured by per capita gross domestic product (GDP). Economic development has an influence on the level of new business activity and its patterns (Sternberg \& Wennekers, 2005). We think that in a more economically advanced country, the pressure to be productive leaves room for entrepreneurs to enter the market when their motive to start a business is opportunity rather than necessity (Wennekers et al., 2005). Therefore, in more highly developed economies, the need to create differentiated businesses driven by an opportunity to enter the market may lead entrepreneurs to form teams as a way of expanding their resources and being more productive. The variable Per capita GDP was calculated as the natural logarithm of GDP at purchasing power parity (PPP) per capita.

Finally, we controlled for the level of financial freedom of the country, being a measure of banking efficiency and the independence of the financial sector from government control. The lower the level of government control over banks, the higher the level of financial freedom, which ensures easier and more effective access to financing for individuals and businesses (Heritage Foundation, 2020). The variable Financial freedom scored countries from the value zero (0) if the level of government control was so repressive as to prohibit financial institutions to the value one hundred (100) if the level of government control was so negligible as to leave financial institutions free to operate fully in market terms.

\section{Descriptive analysis}

Tables 2 and 3 present the descriptive statistics and correlations of the variables used in the analysis, respectively. Table 2 shows that 38 percent of the entrepreneurs of the sample were involved in a team, while the remaining 62 percent were solo entrepreneurs. Concerning our explanatory variables, 41 percent of the sample had attained a post-secondary education or higher, 9 percent had previous intrapreneurial experience, and 28 percent had set up a new business to pursue a business opportunity with the aim of becoming independent or increasing their income. Six percent operated in the extractive sector, 21 percent in the transforming sector, 16 percent in the business-oriented service sector, and 57 percent in the consumer-oriented service sector.

Table 3 shows the correlation matrix. The variables Individualism and Per capita GDP were significantly correlated (0.73), suggesting that societies in developed countries tend to be more individualist than in developing countries. This may have led to some multicollinearity problems in our analysis. However, none of the variance inflation factor (VIF) scores exceeded 5.0, so it was not an issue (Bowerman \& O'Connell, 1990). Likewise, the categories of Work status showed highly significant 
Table 2 Descriptive statistics

\begin{tabular}{lrcccr}
\hline Variable & $\mathrm{N}$ & \multicolumn{1}{l}{ Mean } & Std. Deviation & Min & Max \\
\hline Dependent variable & & & & & \\
Entrepreneurial team & 66,716 & 0.38 & 0.49 & 0.00 & 1.00 \\
Explanatory variables & & & & & \\
Educational level & 66,716 & 0.41 & 0.49 & 0.00 & 1.00 \\
Intrapreneurial experience & 66,716 & 0.09 & 0.29 & 0.00 & 1.00 \\
Opportunity-driven & 66,716 & 0.28 & 0.45 & 0.00 & 1.00 \\
Individualism & 66,716 & 37.27 & 22.97 & 6.00 & 91.00 \\
Control variables & & & & & \\
Gender (1=male) & 66,716 & 0.57 & 0.50 & 0.00 & 1.00 \\
Age & 66,716 & 38.02 & 12.15 & 17.00 & 98.00 \\
Work status & & & & & \\
- Working, full or part-time & 66,716 & 0.90 & 0.30 & 0.00 & 1.00 \\
- Not working & 66,716 & 0.07 & 0.26 & 0.00 & 1.00 \\
- Retired or student & 66,716 & 0.03 & 0.16 & 0.00 & 1.00 \\
Sector & & & & & \\
- Extractive & 66,716 & 0.06 & 0.23 & 0.00 & 1.00 \\
- Transformative & 66,716 & 0.21 & 0.41 & 0.00 & 1.00 \\
- Consumer-oriented & 66,716 & 0.57 & 0.49 & 0.00 & 1.00 \\
- Business services & 66,716 & 0.16 & 0.37 & 0.00 & 1.00 \\
Per-capita GDP & 66,716 & $19,951.22$ & $20,380.02$ & $1,383.17$ & $110,162.10$ \\
Financial freedom & 66,716 & 59.60 & 16.49 & 10.00 & 90.00 \\
\hline
\end{tabular}

negative correlations among them; however, this was not a problem either, as the reference category was excluded from the model estimation. The same applied to the Sector categories. Finally, we can see that our dependent variable was significantly and positively correlated with the explanatory variables Educational level (0.12) and Intrapreneurial experience (0.10), and with the mediator variable Opportunitydriven (0.04).

\section{Results}

The models in Table 4 predict the mediator variable in an incremental approach based on Eq. (1), while the models in Table 5 do the same for the dependent variable based on Eq. (2). The results from both tables are pertinent to the analysis of the (mediated) indirect effect of individual characteristics on entrepreneurial teams through opportunity-driven motivation (hypothesis 3). In addition, the results from Table 5 allow analysis of the effect of educational level and intrapreneurial experience on the likelihood of being a member of an entrepreneurial team (hypotheses 1 and 2), and analysis of the contingent role of individualism as a moderator in such relationships (hypotheses $4 \mathrm{a}$ and $4 \mathrm{~b}$ ). 


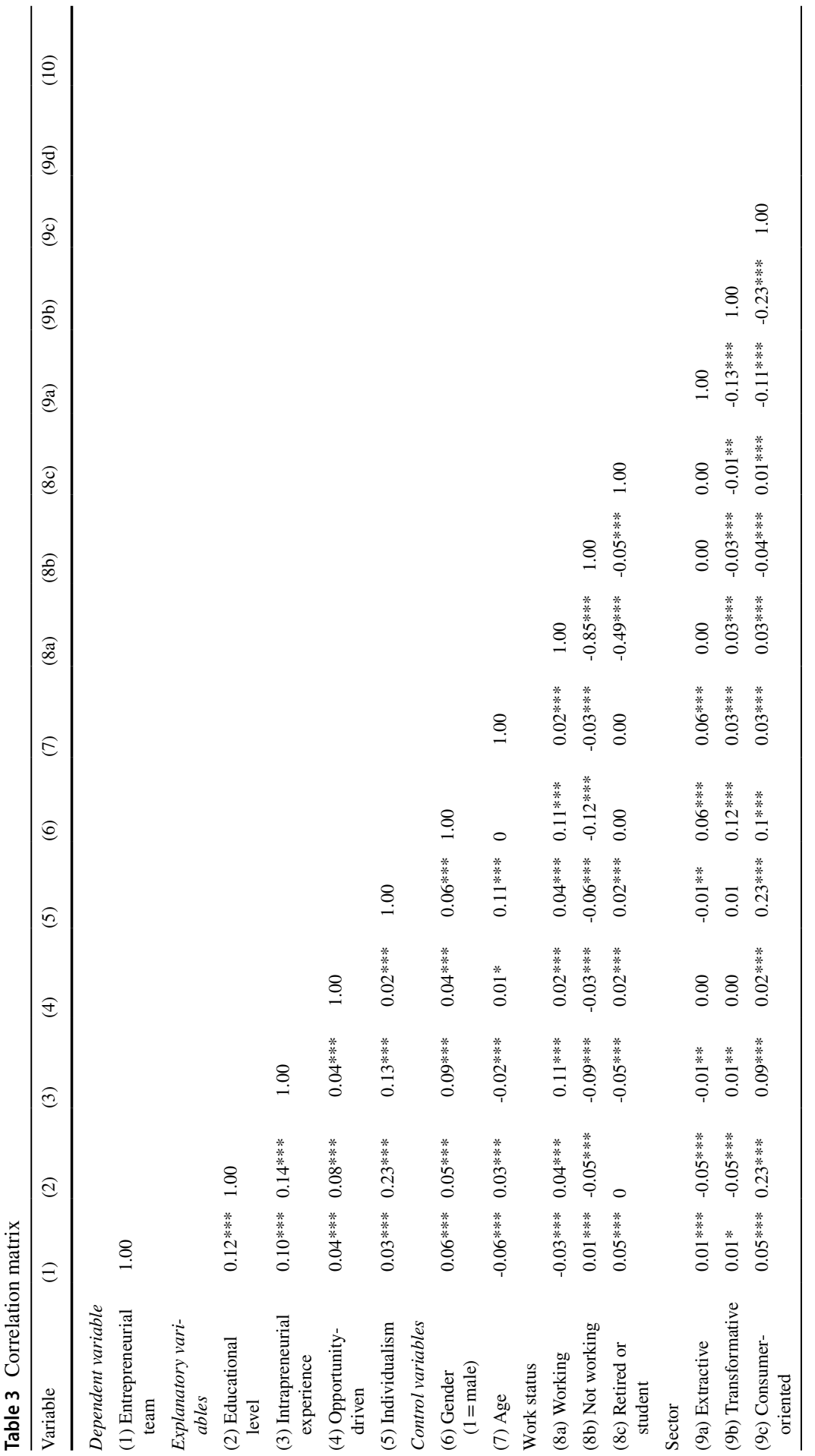




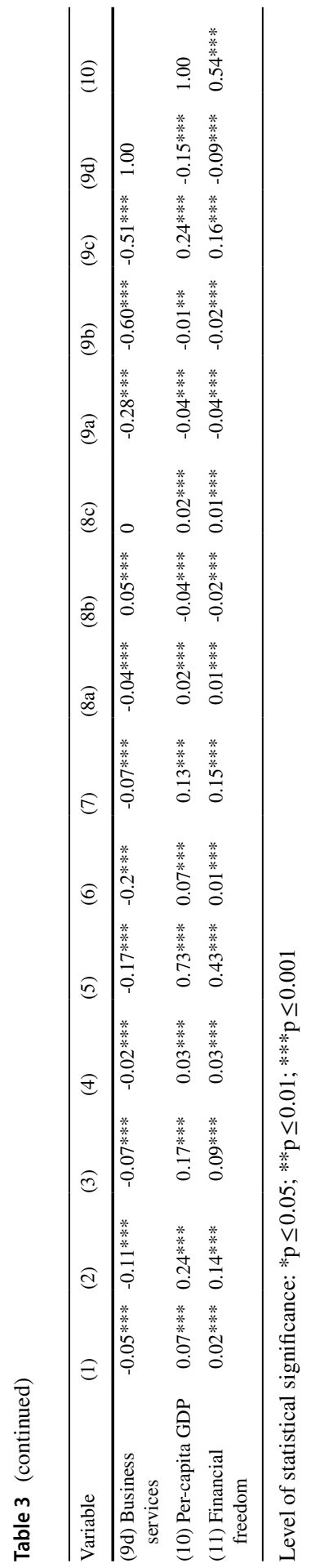


Table 4 Multilevel logistic regression for being opportunity-driven entrepreneur (Mediator)

\begin{tabular}{|c|c|c|c|c|c|c|}
\hline & Model 1 & Model 2 & Model 3 & Model 4 & Model 5 & Model 6 \\
\hline \multicolumn{7}{|l|}{ Explanatory variables } \\
\hline Educational level & & & $\begin{array}{l}1.282 * * * \\
(0.025)\end{array}$ & $\begin{array}{l}1.283^{* * * *} \\
(0.025)\end{array}$ & $\begin{array}{l}1.250 * * * \\
(0.037)\end{array}$ & $\begin{array}{l}1.256 * * * \\
(0.036)\end{array}$ \\
\hline Intrapreneurial experience & & & $\begin{array}{l}1.191 * * * \\
(0.036)\end{array}$ & $\begin{array}{l}1.191 * * * \\
(0.036)\end{array}$ & $\begin{array}{l}1.237 * * * \\
(0.077)\end{array}$ & $\begin{array}{l}1.232 * * \\
(0.079)\end{array}$ \\
\hline \multicolumn{7}{|l|}{ Country context } \\
\hline Individualism & & & & $\begin{array}{l}0.996 \\
(0.003)\end{array}$ & $\begin{array}{l}0.997 \\
(0.003)\end{array}$ & $\begin{array}{l}0.998 \\
(0.003)\end{array}$ \\
\hline \multicolumn{7}{|l|}{ Cross-level interactions } \\
\hline Ed. level x Individualism & & & & & & $\begin{array}{l}0.997 * \\
(0.001)\end{array}$ \\
\hline Intra. exp. x Individualism & & & & & & $\begin{array}{l}1.001 \\
(0.003)\end{array}$ \\
\hline \multicolumn{7}{|l|}{ Control variables } \\
\hline Gender $(1=$ male $)$ & & $\begin{array}{l}1.187 * * * \\
(0.022)\end{array}$ & $\begin{array}{l}1.179 * * * \\
(0.022)\end{array}$ & $\begin{array}{l}1.179 * * * \\
(0.022)\end{array}$ & $\begin{array}{l}1.175 * * * \\
(0.022)\end{array}$ & $\begin{array}{l}1.173 * * * \\
(0.022)\end{array}$ \\
\hline Age & & $\begin{array}{l}0.993^{*} \\
(0.004)\end{array}$ & $\begin{array}{l}0.990^{*} \\
(0.004)\end{array}$ & $\begin{array}{l}0.990 * \\
(0.004)\end{array}$ & $\begin{array}{l}0.990^{*} \\
(0.004)\end{array}$ & $\begin{array}{l}0.990 * \\
(0.004)\end{array}$ \\
\hline $\operatorname{Age}^{2}$ & & $\begin{array}{l}1.000 \\
(0.000)\end{array}$ & $\begin{array}{l}1.000 \\
(0.000)\end{array}$ & $\begin{array}{l}1.000 \\
(0.000)\end{array}$ & $\begin{array}{l}1.000 \\
(0.000)\end{array}$ & $\begin{array}{l}1.000 \\
(0.000)\end{array}$ \\
\hline \multicolumn{7}{|l|}{ Work status: } \\
\hline - Not working & & $\begin{array}{l}0.787 * * * \\
(0.029)\end{array}$ & $\begin{array}{l}0.812 * * * \\
(0.030)\end{array}$ & $\begin{array}{l}0.812 * * * \\
(0.030)\end{array}$ & $\begin{array}{l}0.807 * * * \\
(0.030)\end{array}$ & $\begin{array}{l}0.808 * * * \\
(0.030)\end{array}$ \\
\hline - Retired or student & & $\begin{array}{l}1.185^{* * *} \\
(0.065)\end{array}$ & $\begin{array}{l}1.211^{* * * *} \\
(0.067)\end{array}$ & $\begin{array}{l}1.210 * * * \\
(0.067)\end{array}$ & $\begin{array}{l}1.209 * * * \\
(0.067)\end{array}$ & $\begin{array}{l}1.207 * * * \\
(0.067)\end{array}$ \\
\hline \multicolumn{7}{|l|}{ Sector: } \\
\hline - Extractive & & $\begin{array}{l}0.969 \\
(0.043)\end{array}$ & $\begin{array}{l}1.040 \\
(0.047)\end{array}$ & $\begin{array}{l}1.040 \\
(0.047)\end{array}$ & $\begin{array}{l}1.034 \\
(0.046)\end{array}$ & $\begin{array}{l}1.033 \\
(0.046)\end{array}$ \\
\hline - Transforming & & $\begin{array}{l}0.906^{* * * *} \\
(0.027)\end{array}$ & $\begin{array}{l}0.963 \\
(0.029)\end{array}$ & $\begin{array}{l}0.963 \\
(0.029)\end{array}$ & $\begin{array}{l}0.961 \\
(0.029)\end{array}$ & $\begin{array}{l}0.960 \\
(0.029)\end{array}$ \\
\hline - Consumer-oriented & & $\begin{array}{l}0.923 * * \\
(0.024)\end{array}$ & $\begin{array}{l}0.975 \\
(0.025)\end{array}$ & $\begin{array}{l}0.974 \\
(0.025)\end{array}$ & $\begin{array}{l}0.975 \\
(0.026)\end{array}$ & $\begin{array}{l}0.975 \\
(0.026)\end{array}$ \\
\hline Per-capita GDP & & $\begin{array}{l}1.101^{*} \\
(0.052)\end{array}$ & $\begin{array}{l}1.069 \\
(0.050)\end{array}$ & $\begin{array}{l}1.114 \\
(0.062)\end{array}$ & $\begin{array}{l}1.114^{*} \\
(0.059)\end{array}$ & $\begin{array}{l}1.107 \\
(0.059)\end{array}$ \\
\hline Financial freedom & & $\begin{array}{l}0.998 \\
(0.003)\end{array}$ & $\begin{array}{l}0.998 \\
(0.003)\end{array}$ & $\begin{array}{l}0.998 \\
(0.003)\end{array}$ & $\begin{array}{l}0.999 \\
(0.003)\end{array}$ & $\begin{array}{l}0.999 \\
(0.003)\end{array}$ \\
\hline Intercept & $\begin{array}{l}0.381 * * * \\
(0.019)\end{array}$ & $\begin{array}{l}0.191 * * * \\
(0.079)\end{array}$ & $\begin{array}{l}0.226 * * * \\
(0.092)\end{array}$ & $\begin{array}{l}0.148 * * * \\
(0.076)\end{array}$ & $\begin{array}{l}0.147 * * * \\
(0.073)\end{array}$ & $\begin{array}{l}0.155 * * * \\
(0.077)\end{array}$ \\
\hline \multicolumn{7}{|l|}{$\begin{array}{l}\text { Random effects: variance } \\
\text { components }\end{array}$} \\
\hline Variance of intercept & $\begin{array}{l}0.145^{* * * *} \\
(0.027)\end{array}$ & $\begin{array}{l}0.137 * * * \\
(0.026)\end{array}$ & $\begin{array}{l}0.134 * * * \\
(0.025)\end{array}$ & $\begin{array}{l}1.139 * * * \\
(0.028)\end{array}$ & $\begin{array}{l}1.138 * * * \\
(0.028)\end{array}$ & $\begin{array}{l}1.137 * * * \\
(0.028)\end{array}$ \\
\hline Var. of educational level & & & & & $\begin{array}{l}1.023 * * \\
(0.009)\end{array}$ & $\begin{array}{l}1.019 * \\
(0.008)\end{array}$ \\
\hline Var. of intra. experience & & & & & $\begin{array}{l}1.166^{* * *} \\
(0.051)\end{array}$ & $\begin{array}{l}1.167 * * * \\
(0.051)\end{array}$ \\
\hline Intra-class correlation & 0.045 & 0.042 & 0.040 & 0.039 & 0.038 & 0.038 \\
\hline
\end{tabular}


Table 4 (continued)

\begin{tabular}{lllllll}
\hline & Model 1 & Model 2 & Model 3 & Model 4 & Model 5 & Model 6 \\
\hline $\begin{array}{l}\text { Observations } \\
\text { Level 1: individuals }\end{array}$ & 66,716 & 66,716 & 66,716 & 66,716 & 66,716 & 66,716 \\
$\begin{array}{l}\text { Level 2: countries [country- } \\
\text { year groups] }\end{array}$ & 66 & 66 & 66 & 66 & 66 & 66 \\
$\begin{array}{l}\text { Model fit statistics } \\
\text { Deviance }\end{array}$ & & & & & & \\
Deviance difference & $77,013.26$ & $76,821.16$ & $76,614.39$ & $76,612.63$ & $76,507.76$ & $76,503.28$ \\
\hline
\end{tabular}

Level of statistical significance: $* \mathrm{p} \leq 0.05$; $* * \mathrm{p} \leq 0.01$; $* * * \mathrm{p} \leq 0.001$. Estimates are odds ratios with standard deviations in parentheses

In Table 4, the null model (model 1) had an intraclass correlation (ICC) coefficient of 4.5 percent; in Table 5, it had an ICC coefficient of 6.0 percent. This means that approximately 4.5 percent of the variability in the mediator and 6.0 percent of the variability in the dependent variable were at the country level, supporting the use of multilevel modeling (Snijders \& Bosker, 2012). Other studies using multilevel analysis on entrepreneurship-related topics rely on similar ICC coefficients ranging from 5 to 10 percent (Autio \& Acs, 2010; Hundt \& Sternberg, 2016; Kibler et al., 2018; Morales et al., 2019).

One aspect of interest in Table 5 is the effect of the control variables on the dependent variable. For example, the odds ratio of Gender was above 1 in all models $(p<0.001)$, suggesting that male entrepreneurs were more likely than female entrepreneurs to be members of a team. This is coherent with the idea that men tend to pursue more ambitious ventures which require more resources that can be obtained through entrepreneurial teams (resource acquisition strategy). The odds ratio of Age was significantly below $1(p<0.001)$, showing that the likelihood of the entrepreneur being a member of a team decreased with age. However, the squared term of Age was significantly above $1(p<0.001)$, indicating that there is a threshold after which the likelihood of the entrepreneur being a member of a team increases again with age. The odds ratios for the Work status categories were above $1(\mathrm{p}<0.001)$. Thus, compared with the reference category (i.e., working full- or part-time), for those who were not working, such as homemakers or students, becoming a lone entrepreneur may be more difficult, and therefore the incentive to start a business with other partners seems to be greater. With regard to sector, the business service sector was the reference category. In most models, the odds ratio of the extractive sector was above $1(p<0.001)$, and that of the consumer-oriented sector was below 1 $(p<0.01)$, suggesting that the prevalence of teams was higher in the extractive than in the business service sector, while in consumer-oriented sectors the prevalence was lower. In contrast, the odds ratio of the transforming sector was significantly below 1 in model $2(\mathrm{p}<0.001)$, but it became not significant when we included the explanatory variables in model 3 and subsequent models. This might be because the percentages of entrepreneurs with post-secondary education or higher and with entrepreneurial experience were relatively low in the transforming sector and higher 
Table 5 Multilevel logistic regression for being member of an entrepreneurial team (Outcome)

\begin{tabular}{|c|c|c|c|c|c|c|c|}
\hline & Model 1 & Model 2 & Model 3 & Model 4 & Model 5 & Model 6 & Model 7 \\
\hline \multicolumn{8}{|l|}{$\begin{array}{c}\text { Explanatory } \\
\text { variables }\end{array}$} \\
\hline Educational level & & & $\begin{array}{l}1.418 * * * \\
(0.026)\end{array}$ & $\begin{array}{l}1.411^{* * * *} \\
(0.026)\end{array}$ & $\begin{array}{l}1.411 * * * \\
(0.026)\end{array}$ & $\begin{array}{l}1.354 * * * \\
(0.041)\end{array}$ & $\begin{array}{l}1.376 * * * \\
(0.040)\end{array}$ \\
\hline $\begin{array}{l}\text { Intrapreneurial } \\
\text { experience }\end{array}$ & & & $\begin{array}{l}1.741 * * * \\
(0.050)\end{array}$ & $\begin{array}{l}1.734 * * * \\
(0.050)\end{array}$ & $\begin{array}{l}1.735 * * * \\
(0.050)\end{array}$ & $\begin{array}{l}1.753 * * * \\
(0.102)\end{array}$ & $\begin{array}{l}1.753 * * * \\
(0.104)\end{array}$ \\
\hline \multicolumn{8}{|l|}{ Mediator } \\
\hline Opportunity-driven & & & & $\begin{array}{l}1.111 * * * \\
(0.021)\end{array}$ & $\begin{array}{l}1.111 * * * \\
(0.021)\end{array}$ & $\begin{array}{l}1.102 * * * \\
(0.021)\end{array}$ & $\begin{array}{l}1.102 * * * \\
(0.021)\end{array}$ \\
\hline \multicolumn{8}{|l|}{ Country context } \\
\hline Individualism & & & & & $\begin{array}{l}0.997 \\
(0.003)\end{array}$ & $\begin{array}{l}0.996 \\
(0.003)\end{array}$ & $\begin{array}{l}0.999 \\
(0.003)\end{array}$ \\
\hline \multicolumn{8}{|l|}{$\begin{array}{l}\text { Cross-level } \\
\text { interactions }\end{array}$} \\
\hline $\begin{array}{l}\text { Ed. level x } \\
\text { Individualism }\end{array}$ & & & & & & & $\begin{array}{l}0.996 * * * \\
(0.001)\end{array}$ \\
\hline $\begin{array}{l}\text { Intra. exp. } \mathrm{x} \\
\text { Individualism }\end{array}$ & & & & & & & $\begin{array}{l}1.000 \\
(0.002)\end{array}$ \\
\hline \multicolumn{8}{|l|}{ Control variables } \\
\hline Gender $(1=$ male $)$ & & $\begin{array}{l}1.203^{* * * *} \\
(0.021)\end{array}$ & $\begin{array}{l}1.182 * * * \\
(0.020)\end{array}$ & $\begin{array}{l}1.178 * * * \\
(0.020)\end{array}$ & $\begin{array}{l}1.178 * * * \\
(0.020)\end{array}$ & $\begin{array}{l}1.173 * * * \\
(0.020)\end{array}$ & $\begin{array}{l}1.171 * * * \\
(0.020)\end{array}$ \\
\hline Age & & $\begin{array}{l}0.945^{* * * *} \\
(0.004)\end{array}$ & $\begin{array}{l}0.940^{* * * *} \\
(0.004)\end{array}$ & $\begin{array}{l}0.940 * * * \\
(0.004)\end{array}$ & $\begin{array}{l}0.940 * * * \\
(0.004)\end{array}$ & $\begin{array}{l}0.940 * * * \\
(0.004)\end{array}$ & $\begin{array}{l}0.940 * * * \\
(0.004)\end{array}$ \\
\hline $\mathrm{Age}^{2}$ & & $\begin{array}{l}1.001 * * * \\
(0.000)\end{array}$ & $\begin{array}{l}1.001^{* * * *} \\
(0.000)\end{array}$ & $\begin{array}{l}1.001 * * * \\
(0.000)\end{array}$ & $\begin{array}{l}1.001 * * * \\
(0.000)\end{array}$ & $\begin{array}{l}1.001 * * * \\
(0.000)\end{array}$ & $\begin{array}{l}1.001 * * * \\
(0.000)\end{array}$ \\
\hline \multicolumn{8}{|l|}{ Work status: } \\
\hline - Not working & & $\begin{array}{l}1.163 * * * \\
(0.037)\end{array}$ & $\begin{array}{l}1.252 * * * \\
(0.040)\end{array}$ & $\begin{array}{l}1.258 * * * \\
(0.040)\end{array}$ & $\begin{array}{l}1.258 * * * \\
(0.040)\end{array}$ & $\begin{array}{l}1.255^{* * * *} \\
(0.040)\end{array}$ & $\begin{array}{l}1.256^{* * * *} \\
(0.040)\end{array}$ \\
\hline - Retired or student & & $\begin{array}{l}1.558 * * * \\
(0.081)\end{array}$ & $\begin{array}{l}1.662 * * * \\
(0.087)\end{array}$ & $\begin{array}{l}1.656^{* * * *} \\
(0.087)\end{array}$ & $\begin{array}{l}1.656 * * * \\
(0.087)\end{array}$ & $\begin{array}{l}1.652 * * * \\
(0.087)\end{array}$ & $\begin{array}{l}1.649 * * * \\
(0.087)\end{array}$ \\
\hline \multicolumn{8}{|l|}{ Sector: } \\
\hline - Extractive & & $\begin{array}{l}1.107 * \\
(0.045)\end{array}$ & $\begin{array}{l}1.243 * * * \\
(0.052)\end{array}$ & $\begin{array}{l}1.242 * * * \\
(0.052)\end{array}$ & $\begin{array}{l}1.242 * * * \\
(0.052)\end{array}$ & $\begin{array}{l}1.231 * * * \\
(0.051)\end{array}$ & $\begin{array}{l}1.229 * * * \\
(0.051)\end{array}$ \\
\hline - Transforming & & $\begin{array}{l}0.886^{* * * *} \\
(0.024)\end{array}$ & $\begin{array}{l}0.974 \\
(0.027)\end{array}$ & $\begin{array}{l}0.975 \\
(0.027)\end{array}$ & $\begin{array}{l}0.975 \\
(0.027)\end{array}$ & $\begin{array}{l}0.971 \\
(0.027)\end{array}$ & $\begin{array}{l}0.969 \\
(0.027)\end{array}$ \\
\hline $\begin{array}{l}\text { - Consumer- } \\
\text { oriented }\end{array}$ & & $\begin{array}{l}0.859 * * * \\
(0.021)\end{array}$ & $\begin{array}{l}0.934 * * \\
(0.023)\end{array}$ & $\begin{array}{l}0.935 * * \\
(0.023)\end{array}$ & $\begin{array}{l}0.934 * * \\
(0.023)\end{array}$ & $\begin{array}{l}0.934 * * \\
(0.023)\end{array}$ & $\begin{array}{l}0.934 * * \\
(0.023)\end{array}$ \\
\hline Per-capita GDP & & $\begin{array}{l}1.310^{* * * *} \\
(0.066)\end{array}$ & $\begin{array}{l}1.242 * * * \\
(0.061)\end{array}$ & $\begin{array}{l}1.240 * * * \\
(0.061)\end{array}$ & $\begin{array}{l}1.291 * * * \\
(0.077)\end{array}$ & $\begin{array}{l}1.306^{* * * *} \\
(0.080)\end{array}$ & $\begin{array}{l}1.308 * * * \\
(0.078)\end{array}$ \\
\hline Financial freedom & & $\begin{array}{l}0.991 * * \\
(0.003)\end{array}$ & $\begin{array}{l}0.991 * * * \\
(0.003)\end{array}$ & $\begin{array}{l}0.991 * * \\
(0.003)\end{array}$ & $\begin{array}{l}0.992 * * \\
(0.003)\end{array}$ & $\begin{array}{l}0.991 * * \\
(0.003)\end{array}$ & $\begin{array}{l}0.992 * * \\
(0.003)\end{array}$ \\
\hline Intercept & $\begin{array}{l}0.637 * * * \\
(0.037)\end{array}$ & $\begin{array}{l}0.290 * * \\
(0.128)\end{array}$ & $\begin{array}{l}0.400^{*} \\
(0.173)\end{array}$ & $\begin{array}{l}0.392 * \\
(0.169)\end{array}$ & $\begin{array}{l}0.260 * \\
(0.141)\end{array}$ & $\begin{array}{l}0.244 * \\
(0.136)\end{array}$ & $\begin{array}{l}0.243 * * \\
(0.133)\end{array}$ \\
\hline \multicolumn{8}{|l|}{ Random effects: } \\
\hline $\begin{array}{c}\text { Variance of } \\
\text { intercept }\end{array}$ & $\begin{array}{l}0.209^{* * * *} \\
(0.038)\end{array}$ & $\begin{array}{l}0.163^{* * * *} \\
(0.031)\end{array}$ & $\begin{array}{l}0.156^{* * * *} \\
(0.029)\end{array}$ & $\begin{array}{l}0.155^{* * * *} \\
(0.029)\end{array}$ & $\begin{array}{l}0.151 * * * \\
(0.029)\end{array}$ & $\begin{array}{l}0.156^{* * * *} \\
(0.030)\end{array}$ & $\begin{array}{l}0.151 * * * \\
(0.029)\end{array}$ \\
\hline
\end{tabular}


Table 5 (continued)

\begin{tabular}{|c|c|c|c|c|c|c|c|}
\hline & Model 1 & Model 2 & Model 3 & Model 4 & Model 5 & Model 6 & Model 7 \\
\hline $\begin{array}{l}\text { Var. of educational } \\
\text { level }\end{array}$ & & & & & & $\begin{array}{l}0.028 * * \\
(0.010)\end{array}$ & $\begin{array}{l}0.024 * * \\
(0.009)\end{array}$ \\
\hline $\begin{array}{l}\text { Var. of intra. } \\
\text { experience }\end{array}$ & & & & & & $\begin{array}{l}0.131 * * * \\
(0.036)\end{array}$ & $\begin{array}{l}0.132 * * * \\
(0.037)\end{array}$ \\
\hline $\begin{array}{l}\text { Intra-class } \\
\text { correlation }\end{array}$ & 0.060 & 0.047 & 0.045 & 0.045 & 0.044 & 0.045 & 0.044 \\
\hline \multicolumn{8}{|l|}{ Observations } \\
\hline $\begin{array}{l}\text { Level 1: } \\
\text { individuals }\end{array}$ & 66,716 & 66,716 & 66,716 & 66,716 & 66,716 & 66,716 & 66,716 \\
\hline Level 2: countries & 66 & 66 & 66 & 66 & 66 & 66 & 66 \\
\hline \multicolumn{8}{|l|}{ Model fit statistics } \\
\hline Deviance & $85,836.05$ & $84,977.37$ & $84,180.13$ & $84,148.24$ & $84,146.76$ & $84,019.57$ & $84,002.65$ \\
\hline $\begin{array}{l}\text { Deviance } \\
\text { difference }\end{array}$ & - & $858.68^{* * *} *$ & $797.23 * * *$ & $31.89 * * *$ & 1.48 & $127.18 * * *$ & $16.92 * * *$ \\
\hline
\end{tabular}

Level of statistical significance: ${ }^{*} \mathrm{p} \leq 0.05$; $* * \mathrm{p} \leq 0.01$; $* * * \mathrm{p} \leq 0.001$. Estimates are odds ratios with standard deviations in parentheses

in the business service sector. Thus, after accounting for these differences, the likelihood of the entrepreneur being a member of a team was equal between those operating in both sectors. Finally, Per capita GDP had an odds ratio above 1 in all the models $(p<0.001)$. This result means that entrepreneurial teams were more prevalent in developed countries. Finally, Financial freedom showed odds ratios below 1 $(p<0.01)$, which was consistent with the notion that easier access to financing made people more likely to start a business alone.

\section{The effect of individual characteristics on entrepreneurial teams}

Model 3 in Table 5 adds the explanatory variables to estimate the effect of individual characteristics on entrepreneurial teams. The deviance difference against model 2 was significant ( $p<0.001$ ), suggesting that, after accounting for the control variables, the explanatory variables improved the goodness of fit. The results showed that the likelihood of the entrepreneur being a member of a team increased with educational level and intrapreneurial experience. In particular, Educational level presented a significant odds ratio above 1 in model $3(p<0.001)$, which was consistent across subsequent models (see Table 5). Thus, the higher the educational level of the entrepreneur, the higher the likelihood of them being part of a team (instead of pursuing a business opportunity alone). This finding provides support to our hypothesis 1 . The odds ratio of Intrapreneurial experience was also significantly above 1 in model $3(p<0.001)$ and consistent across subsequent models, which gives support to our hypothesis 2 . In other words, intrapreneurial experience increases the likelihood of being involved in a team. 
Table 6 Analysis of opportunity-driven motivation as mediator in the relationship between educational level and team formation

\begin{tabular}{lllll}
\hline Type of effect & Point estimate & p- value & \multicolumn{2}{l}{$\begin{array}{l}\text { 95\% confidence } \\
\text { interval }\end{array}$} \\
\cline { 3 - 5 } & & & Lower & Upper \\
\hline Mediation effect & 0.001246 & 0.000 & 0.000776 & 0.001796 \\
Direct effect & 0.077844 & 0.000 & 0.069623 & 0.085985 \\
$\begin{array}{l}\text { Total effect } \\
\text { \% of total effect } \\
\text { via mediation }\end{array}$ & 0.079014 & 0.000 & 0.070834 & 0.087081 \\
\hline
\end{tabular}

95\% confidence interval of the point estimate computed with the quasi-Bayesian Monte Carlo method (Imai et al., 2010; Tingley et al., 2014) using 1,000 subsample simulations from the total sample $(\mathrm{N}=66,719)$

\section{Mediation effect of opportunity-driven motivation}

As model 3 in Table 4 reveals, the probability that entrepreneurs were opportunitydriven significantly increased with Educational level $(p<0.001)$ and Intrapreneurial experience $(p<0.001)$. The deviance difference against model 2 was significant $(p<0.001)$, suggesting that the explanatory variables improved the goodness of fit. On the other hand, in model 4 of Table 5, opportunity rather than necessity as the main motive to start a business significantly increased the probability that the entrepreneurs were member of a team $(p<0.001)$. In this case, the deviance difference against model 3 was significant $(p<0.001)$, suggesting that the mediator variable improved the goodness of fit.

To test hypothesis 3 , we took these results and empirically computed the mediation effects as $a_{1} * b$, where $a_{1}$ is the effect of each predictor on the mediator (i.e., coefficients of Educational level and Intrapreneurial experience in model 3 of Table 4), and $b$ is the effect of the mediator on the outcome (i.e., coefficient of Opportunity-driven in model 4 of Table 5). Tables 6 and 7 report the estimates of the mediation analysis using the quasi-Bayesian Monte Carlo method (Imai et al.,

Table 7 Analysis of opportunity-driven motivation as mediator in the relationship between intrapreneurial experience and team formation

\begin{tabular}{lllll}
\hline Type of effect & Estimate & p- value & \multicolumn{2}{l}{$\begin{array}{l}\text { 95\% confidence } \\
\text { interval }\end{array}$} \\
\cline { 3 - 5 } & & & Lower & Upper \\
\hline Mediation effect & 0.000902 & 0.000 & 0.000480 & 0.001368 \\
Direct effect & 0.123176 & 0.000 & 0.110866 & 0.135884 \\
$\begin{array}{l}\text { Total effect } \\
\text { \% of total effect } \\
\text { via mediation }\end{array}$ & 0.124033 & 0.000 & 0.111595 & 0.136752 \\
\hline
\end{tabular}

95\% confidence interval of the point estimate computed with the quasi-Bayesian Monte Carlo method (Imai et al., 2010; Tingley et al., 2014) using 1,000 simulations from the total sample $(\mathrm{N}=66,719)$ 
2010; Tingley et al., 2014). In the relationship between educational level and the likelihood of the entrepreneur being a member of a team, the mediation effect of opportunity-driven motivation was 0.0012 and ranged within a 95 percent confidence interval that did not include zero (see Table 6). Likewise, opportunity-driven motivation mediated the relationship between intrapreneurial experience and entrepreneurial team with an indirect effect of 0.0009 , which ranged from 0.0005 to 0.0013 (see Table 7). Thus, the mediation effect in both cases was significant $(\mathrm{p}<0.001)$. Nonetheless, most of the effect of the predictors on the outcome was accounted for by the direct effect without passing through the mediator. Therefore, the mediation effects were partial, since the direct effects of educational level (Table 6) and entrepreneurial experience (Table 7) on entrepreneurial team were larger and significant $(\mathrm{p}<0.001)$. To be precise, the mediation role of opportunitydriven motivation represented an indirect effect that was around 1.5 percent of the total effect of educational level and 0.7 percent of the total effect of intrapreneurial experience on entrepreneurial team. ${ }^{3}$ Despite the low size, these partial mediation effects were significant. Accordingly, these findings gave some support to hypotheses 3-that is, being an opportunity-driven entrepreneur mediated the relationship between individual characteristics and the probability of being a member of an entrepreneurial team, though the effect was partial.

\section{Moderating effect of individualism}

Model 5 in Table 5 shows that the total effect of Individualism on Entrepreneurial team is not significant. However, we were mainly interested in its moderation effect. Model 6 is an extension of model 5 that allows the slope coefficients of the explanatory variables (level 1) to vary across countries (level 2). The deviance difference of model 6 against model 5 indicates that the goodness of fit significantly improved $(p<0.001)$ when we added the random effects (see Table 5). Indeed, the variance of the coefficients was significant for both Educational level $(p<0.01)$ and Intrapreneurial experience $(p<0.001)$, meaning that their random effects were different from zero. In other words, the slope coefficients of the explanatory variables significantly varied across countries, and the context exerted a moderation effect that would explain such variance.

In model 7, we added the interaction terms among our two explanatory variables and Individualism. While the main effect of Individualism remained insignificant in this final model, the odds ratio of the interaction term between Educational level and Individualism was significantly below $1(p<0.001)$, suggesting that the influence of educational level on the likelihood of creating a venture as a member of a team was negatively moderated by individualism. Using the 'pick-a-point' approach, which is common in the entrepreneurship literature (e.g. Meoli et al., 2020), we plotted the predicted marginal effects of educational level on entrepreneurial team at high (one s.d. above the mean), mean, and low (one s.d. below the mean) values of individualism (see Fig. 3, panel A). This simple slope analysis suggested that the effect

\footnotetext{
3 The percentage explained by the indirect effect was estimated as follows: $a * b /(a * b+c)$.
} 

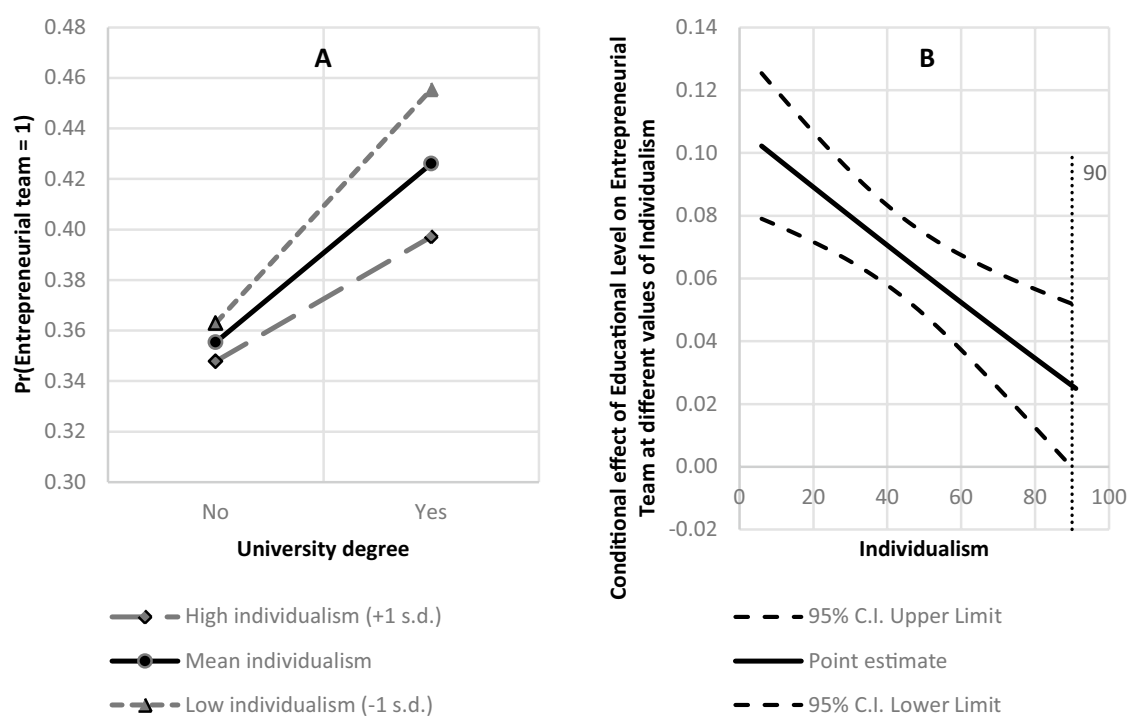

Note: Parameter estimates from model 7 of Table 5

Fig. 3 Moderation of the individualist context on the marginal effects of educational level on entrepreneurial team: Slopes for the mean and \pm 1 s.d. of the moderator (A), and Johnson-Neyman regions of significance for the conditional effect (B) Note: Parameter estimates from model 7 of Table 5

of educational level slightly differed between high and low levels of individualism. In addition, we formally tested this interaction using the Johnson-Neyman technique (Hayes, 2018) to derive regions of significance for the conditional effect of the predictor on the outcome at different values of the moderator. Panel B of Fig. 3 plots the conditional effect (continuous line) of educational level on entrepreneurial team across the distribution of individualism, as well as the upper and lower limits (dashed lines) of a 95 percent confidence interval. As can be seen, the conditional effect is positive and significantly different from zero, but it significantly decreases with higher levels of individualism and becomes not significant when the individualism index of the country is greater than 90. This finding supports hypothesis $4 \mathrm{a}$.

In contrast, the odds ratio of the interaction term between Intrapreneurial experience and Individualism was not significant (see model 7 in Table 5). Thus, although it significantly varied across countries, the variance of the slope coefficient for Intrapreneurial experience was not explained by the level of individualism of the context. The slopes of the marginal effects of intrapreneurial experience on entrepreneurial team did not differ between high and low levels of individualism (see Fig. 4, panel A). Moreover, the regions of significance derived from the Johnson-Neyman technique show that this effect is significantly different from zero, but it is constant across the distribution of individualism. Thus, hypothesis $4 \mathrm{~b}$ is not supported; however, our finding that the coefficient of Intrapreneurial experience had significant random effects reveals that the context exerted a contingent role that deserves further research. 

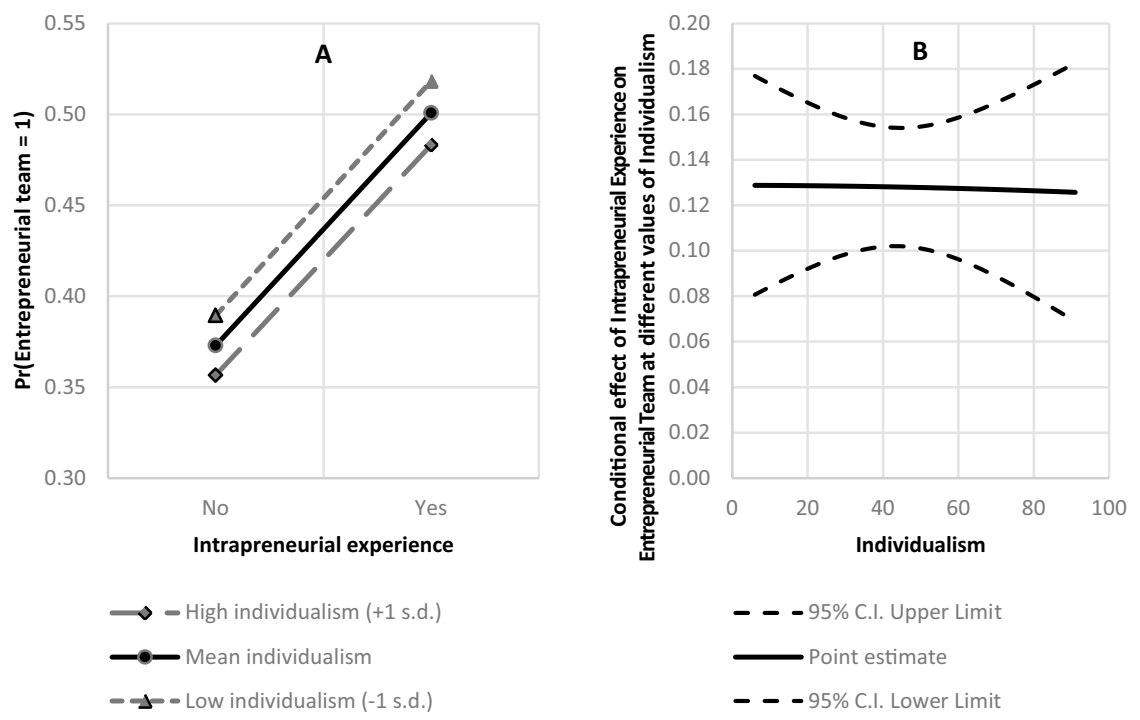

Note: Parameter estimates from model 7 of Table 5

Fig. 4 Moderation of the individualist context on the marginal effects of intrapreneurial experience on entrepreneurial team: Slopes for the mean and \pm 1 s.d. of the moderator (A), and Johnson-Neyman regions of significance for the conditional effect (B) Note: Parameter estimates from model 7 of Table 5

\section{Robustness checks}

We ran several robustness tests to confirm the main findings of our results. ${ }^{4}$ Firstly, we tested whether the results for the moderation role of individualism held not only for the direct effect of the predictors on the outcome, but also for the indirect effects through the mediator. Thus, we computed the conditional mediation effect at different values of the moderator ${ }^{5}$ and found that it significantly decreased as individualism at the country level increased in the case of educational level (see Fig. 5, panel B), but it was not significant in the case of intrapreneurial experience (see Fig. 5, panel B). This corroborated our prior findings on the role of individualism as a moderator.

Secondly, compared with those who are just beginning the business creation process, those entrepreneurs who already owned and managed a new business may have taken the steps to form a team based on the outcomes of the preceding nascent phase

\footnotetext{
${ }^{4}$ Tables with specific tests are not shown due to space constraints. The full results for each robustness test are available from the authors upon request.

${ }^{5}$ The conditional mediation is defined as $\left(a_{1}+a_{2} Z_{j}\right) * b$, where $a_{1}$ is the effect of each predictor on the mediator (i.e., coefficients for Educational level and Intrapreneurial experience in model 6 of Table 4); $a_{2}$ is the effect of the moderator on the relationship between the predictors and the mediator (i.e., coefficients for interaction term Educational level $\mathrm{x}$ Individualism and Intrapreneurial experience $\mathrm{x}$ Individualism in model 6 of Table 4); and $b$ is the effect of the mediator on the outcome after controlling for the effect of the moderator (i.e., coefficient for Opportunity-driven in model 7 of Table 5).
} 

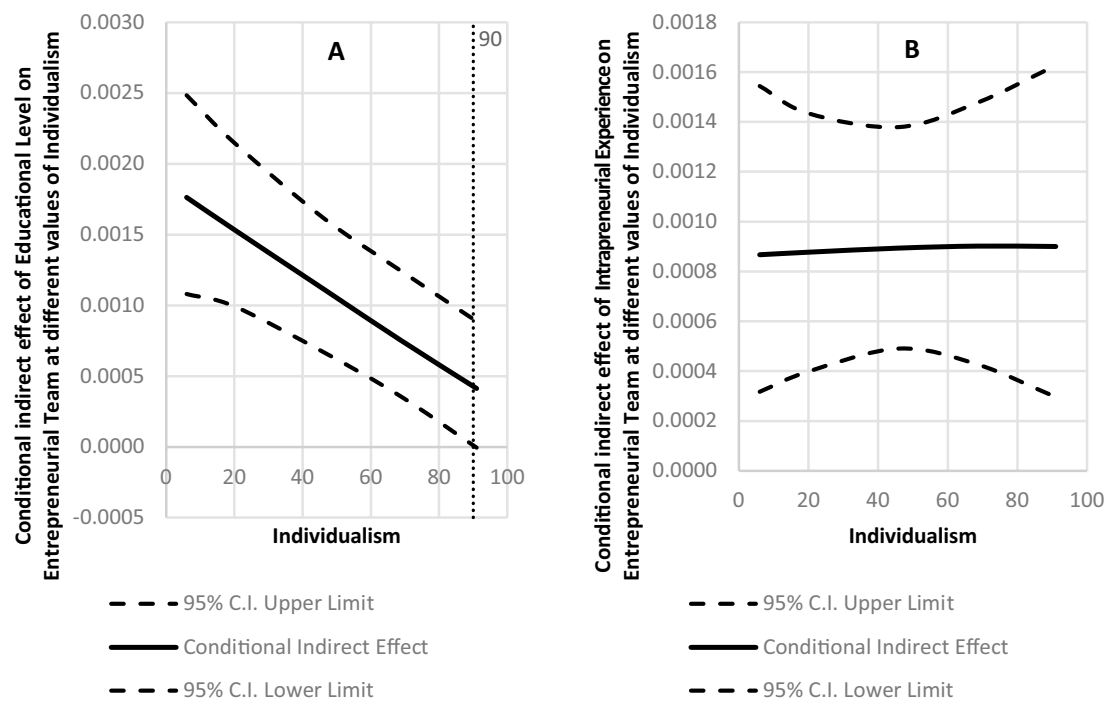

Note: $95 \%$ confidence interval of the point estimate at different values of the moderator computed with the quasi-Bayesian Monte Carlo method (Imai et a., 2010; Tingley et al., 2014) using 1,000 subsample simulations from the total sample $(\mathrm{N}=66,719)$ for each estimation.

Fig. 5 Johnson-Neyman regions of significance for the conditional indirect effects of the predictors on the outcome through the mediator at different values of the moderator (moderated mediation) Note: $95 \%$ confidence interval of the point estimate at different values of the moderator computed with the quasiBayesian Monte Carlo method (Imai et al., 2010; Tingley et al., 2014) using 1,000 subsample simulations from the total sample $(\mathrm{N}=66,719)$ for each estimation

(Lazar et al., 2020). Accordingly, the factors explaining team formation may differ across different phases. To confirm that our results do not depend on potential systematic differences among phases, we split the sample into nascent and new entrepreneurs and performed separate multilevel logistic regressions. The new results did not differ substantially from the results discussed above. In general, the sign, size, and significance level of the coefficients were similar for both Educational level and Intrapreneurial experience. Therefore, these individual characteristics increased the likelihood of the entrepreneur being a member of an entrepreneurial team regardless of the phase in the business creation process. The only difference was that the interaction term between Educational level and Individualism became less significant in the sample of new entrepreneurs (odds ratio of 0.997, $\mathrm{p}<0.10$ ) compared with the sample of nascent entrepreneurs (odds ratio of $0.996, p<0.01$ ), which suggests that the negative moderation effect of an individualistic context was more pronounced in the earlier phases.

Thirdly, due to the complexity of estimating a multilevel mediation model with cross-level moderation effects, we operationalized Educational level as a dummy variable that accounted for post-secondary education or higher to ease the estimation and interpretation of the results. This operationalization was not very nuanced in comparison with other prior studies (Colombo \& Grilli, 2010). However, we performed additional multilevel logistic regressions including a categorical variable 
that distinguished five levels of education, namely none, some secondary, secondary, post-secondary, and graduate study. The new results were consistent with the results discussed above. In particular, compared with no or some secondary study (i.e., the reference category), the attainment of higher levels of education increased the likelihood of the entrepreneur being a member of a team rather than a solo entrepreneur (Secondary studies showed odds ratios of 1.191 to $1.214, \mathrm{p}<0.001$; Post-secondary studies showed odds ratios of 1.531 to $1.549, p<0.001$; and Graduate studies showed odds ratios of 1.793 to $1.929, p<0.001)$. However, the negative moderation of Individualism was significant only for the relationship between Graduate studies and Entrepreneurial team (odds ratio of $0.993, p<0.001$ ), suggesting that individualistic contexts decrease the likelihood that entrepreneurs who have studied at graduate level will be members of teams.

Finally, we restricted the dependent variable by distinguishing between two extreme categories: solo entrepreneur versus entrepreneurial team. However, the dynamics of the entrepreneurial teams and their drivers may differ depending on the number of members, as there are usually additions and attritions during the team formation process (Lazar et al., 2020). We relaxed the operationalization of the dependent variable and performed multilevel ordered logistic regressions to predict the number of entrepreneurial team members according to four categories, namely solo entrepreneur, two entrepreneurs, three or four entrepreneurs, and five or more entrepreneurs. The sign, size, and significance level of the coefficient estimates from multilevel ordered logistic regressions were very similar for both Educational level and Intrapreneurial experience, as well as for the interaction between Educational level and Individualism. Thus, the main findings of our results are robust to the alternative operationalization of the dependent variable.

\section{Discussion and conclusions}

One of the great myths of entrepreneurship is the notion of the entrepreneur as a lone hero (Cooney, 2005). Peterson (1988), among others, believes that this is a consequence of the fact that the majority of the related research has been carried out in the United States, which has a strong individualist culture. Although many new ventures are founded by teams, entrepreneurial teams only started to attract scholarly attention in the late 1970 s, when scholars started challenging the myth of the lone entrepreneur. In recent decades, an emerging literature on entrepreneurial teams has addressed questions such as the why, how, when, and where of their formation. As Lazar et al. (2020, p. 29) explain, "entrepreneurial team formation research is a fertile ground that has met merely a fraction of its potential to advance important knowledge in the field." We have addressed the 'why' question-that is, why certain individuals are involved in a new venture with partners.

The main objective of this paper was to understand why an individual is involved in an entrepreneurial activity as member of a team rather than as a solo entrepreneur, and how the degree of individualism of the society moderates such an influence. In general, our results indicate that individuals with a higher educational level and with intrapreneurial experience are more likely to be part of a team, but these 
findings are contingent upon the degree of individualism within a society. This cultural dimension has helped us to explain some of the contradictory results in the previous literature.

In our theoretical framework, we have argued that entrepreneurs with higher levels of education have a more specific set of skills than individuals without formal studies, so they need to find people who have particular abilities and competencies that complement their human capital (Hsu \& Chen, 2021; Kato et al., 2015). Similarly, the educational process improves the individual's network of contacts (Kacperczyk, 2012; Weenberg et al., 2011), which, in turn, improves the likelihood of finding the right associates for a new venture. Indeed, our results show that a higher standard of education increases the entrepreneur's likelihood of creating a business as a member of a team. Another individual characteristic that strongly affects involvement in a team is intrapreneurial experience. People who have this experience are able to identify the advantages and disadvantages of working as part of a team, so they know better how to manage interactions among team members. Furthermore, intrapreneurial experience expands individuals' contact network, facilitating the search for good partners. Our results support this kind of reasoning, showing that entrepreneurs with intrapreneurial experience are more likely to be involved in an entrepreneurial team than those without.

However, our findings also show that the relationships among these individual characteristics and involvement in a team are mediated by the motivation of the individual. As we have explained, individuals endowed with education and experience are attractive in the job market, so they are less likely to be pushed into entrepreneurship by necessity. People characterized by higher levels of human capital are likely to become entrepreneurs only if they can act upon value-creating opportunities, and to identify and/or exploit these opportunities they need partners. Furthermore, we have introduced the individualism dimension as a contextual factor that may help to reconcile the inconsistent theoretical arguments in previous literature. Our results show that the effect of educational level on team involvement is less pronounced in individualist contexts, where highly qualified entrepreneurs have an incentive to manage a business alone.

We have relied on a moderated mediation analysis under a multilevel approach to assess the influence of individual characteristics on the decision to form an entrepreneurial team via an opportunity-driven motivation, taking into account the contingent role of individualism at the country level. Our findings present several contributions. Firstly, we have argued that the degree of individualism within a society is a particularly relevant dimension when analyzing why some individuals are more likely to get involved in a new business with partners rather than alone. In this regard, our findings suggest that the probability of being a member of an entrepreneurial team increases with higher levels of education, but the size and significance of this effect decreases with the degree of individualism of the country, which is coherent with the varying nature of entrepreneurship across different cultural contexts (De Clercq et al., 2013; Fuentelsaz et al., 2018). Besides contributing to this stream of research, we add to entrepreneurship literature on human capital, exploring the influence of human capital on getting involved in a team in the early stages of the venturing process. Likewise, we contribute to the career perspective on 
entrepreneurship, explaining how the motivation to enter an entrepreneurial career is affected by prior investment in human capital, which in turn affects involvement in a new venture as part of a team.

Our second contribution is a deeper understanding of the mediation role played by the individual's motivation to enter into entrepreneurship. The previous literature has shown how individuals' motivations affect the profile of new ventures and their economic and social impact. Our results have shown that an opportunitydriven motivation partially mediates the relationships between individual factors and involvement in an entrepreneurial team. Individuals with a high educational level and intrapreneurial experience are more likely to be opportunity-driven entrepreneurs, which, in turn, positively predisposes them to join entrepreneurial teams rather than start a business alone. This partial mediation suggests that there may be other mechanisms that explain the human capital-team relationship. Future research can deepen this issue. For instance, high levels of education and experience may attract external team members, who may think that a business project led by an individual with high human capital will be more successful. Our third contribution is the measurement of empirical relationships among individuals' attributes and their propensity to create an entrepreneurial team. The wide range of countries that we employed in our analysis (66 in all) and the time horizon selected (four years) allows our results at the individual level to be generalized with the boundary conditions defined by the cross-level interactions (Aguinis et al., 2013).

Our analysis is particularly valuable for policymakers, as it could inform them as to why some individuals with certain characteristics have a greater propensity to be involved in entrepreneurship in teams rather than alone, how such a propensity works through the type of entrepreneurial motivation of the individual, and what context conditions make such a propensity weaker or stronger. Previous research has stressed that the social and economic contribution of teams is higher, so a sound public policy might involve the promotion of entrepreneurial projects with several partners, instead of individual projects with low value added (Shane, 2009). Another strategy might be to identify individuals with high levels of educational and intrapreneurial experience and to encourage them to become entrepreneurs. They would be more likely to create entrepreneurial teams because they know which additional resources they need to implement their ideas, and they have better networks of potential partners. Furthermore, as we have seen, they are more opportunity-driven, which, in turn, positively affects the creation of entrepreneurial teams. Additionally, these findings show the importance of higher education fostering entrepreneurship, because highly educated people are more likely to pursue opportunity entrepreneurship and recruit team members. On the other hand, our results show that necessity entrepreneurship is more likely among individuals with lower human capital and that they are more involved in the solo business process. Policymakers should probably be more concerned about the fact that necessity entrepreneurs engage in collaboration to create more effective solutions to unemployment. Nevertheless, policymarkers have to take into account that the cultural profile of their respective countries is an important influence. Even if previous research has shown that individualist countries are generally more entrepreneurial than collectivist countries, our study shows that in individualist countries, highly educated individuals may have a reduced 
tendency to enter into the entrepreneurial process with partners. Early equity investors have to be aware that the profile of the entrepreneur highly influences his/her involvement in an entrepreneurial team and that a good business opportunity is more likely to be exploited by a team than by an individual.

Finally, we highlight some of the limitations of our study, which may point to avenues for future research. Firstly, the involvement in a new venture as a part of a team instead of doing it alone is a complex decision that can involve many different factors. We have focused on two important individual factors, educational level and intrapreneurial experience, and a moderating variable, the level of individualism within a country. However, introducing another contextual factor that measures the formal institutional context may be a good way of expanding our framework, such as the availability of financing. Individuals may prefer to create a venture alone because they do not require the monetary resources that other people are able to provide. Secondly, GEM data are cross-sectional, so they do not allow the measurement of changes in the entrepreneurial team over time (Chandler et al., 2005) or the unequivocal operationalization of the causal sequence of events. Even though this limitation does not necessarily invalidate the results of our mediation analysis (Hayes, 2018), longitudinal data would help to better understand this phenomenon. Indeed, the entrepreneurial process is a long process, so there may be many changes in the team composition from the point at which the idea emerges to the point at which the business is profitable. Partners can be found in an early stage of the process or in the late stages, while others may leave as the business is being created. To study these aspects, the Panel Study of Entrepreneurial Dynamics (PSED) data may be useful.

Thirdly, although in a robustness check we studied the explanatory factors that influence the number of team members as a categorical variable rather than a binary variable, investigating the factors that inhibit entrepreneurial teams from becoming larger may be a fruitful avenue of research. Furthermore, our study relies on Hofstede's cultural value dimension of individualism, which is the most popular. Even if some authors argue that cultural values should represent a stable trait, a growing number of studies have found that the concept of a national culture is rapidly changing. Future research needs to take this into account. Finally, the GEM data do not include important details regarding intrapreneurial experience, such as the level occupied by intrapreneurs within the organization or the type of managerial or entrepreneurial education that entrepreneurs have undergone. Future researchers might employ more accurate measures of intrapreneurial experience.

Funding Open Access funding provided thanks to the CRUE-CSIC agreement with Springer Nature.

Open Access This article is licensed under a Creative Commons Attribution 4.0 International License, which permits use, sharing, adaptation, distribution and reproduction in any medium or format, as long as you give appropriate credit to the original author(s) and the source, provide a link to the Creative Commons licence, and indicate if changes were made. The images or other third party material in this article are included in the article's Creative Commons licence, unless indicated otherwise in a credit line to the material. If material is not included in the article's Creative Commons licence and your intended use is not permitted by statutory regulation or exceeds the permitted use, you will need to obtain permission directly from the copyright holder. To view a copy of this licence, visit http://creativecommons.org/ licenses/by/4.0/. 


\section{References}

Aguinis, H., Gottfredson, R. K., \& Culpepper, S. A. (2013). Best-Practice Recommendations for Estimating Cross-Level Interaction Effects Using Multilevel Modeling. Journal of Management, 39(6), 1490-1528.

Aldrich, H. E., \& Kim, P. H. (2007). Small worlds, infinite possibilities? How social networks affect entrepreneurial team formation and search. Strategic Entrepreneurship Journal, 1(1-2), 147-165.

Arenius, P., \& De Clercq, D. (2005). A Network-based Approach on Opportunity Recognition. Small Business Economics, 24(3), 249-265.

Arenius, P., \& Minniti, M. (2005). Perceptual Variables and Nascent Entrepreneurship. Small Business Economics, 24(3), 233-247.

Audretsch, D. B., Klomp, L., Santarelli, E., \& Thurik, A. R. (2004). Gibrat's Law: Are the Services Different? Review of Industrial Organization, 24(3), 301-324.

Autio, E., \& Acs, Z. (2010). Intellectual property protection and the formation of entrepreneurial growth aspirations. Strategic Entrepreneurship Journal, 4(3), 234-251.

Autio, E., Pathak, S., \& Wennberg, K. (2013). Consequences of cultural practices for entrepreneurial behaviors. Journal of International Business Studies, 44(4), 334-362.

Bauer, D. J., Preacher, K. J., \& Gil, K. M. (2006). Conceptualizing and testing random indirect effects and moderated mediation in multilevel models: New procedures and recommendations. Psychological Methods, 11(2), 142-153.

Block, J. H., \& Landgraf, A. (2016). Transition from part-time entrepreneurship to full-time entrepreneurship: The role of financial and non-financial motives. International Entrepreneurship and Management Journal, 12(1), 259-282.

Bosma, N. (2013). The Global Entrepreneurship Monitor (GEM) and Its Impact on Entrepreneurship Research. Foundations and Trends in Entrepreneurship, 9(2), 143-248.

Bosma, N., Stam, E., \& Wennekers, S. (2010). Intrapreneurship versus entrepreneurship in high-and low-income countries Entrepreneurship, People and Organizations. Frontiers in European Entrepreneurship Research. Cheltenham: Edward Elgar

Bowerman, B. L., \& O'Connell, R. T. (1990). Linear Statistical Models: An Applied Approach (2nd ed.). Duxbury Press.

Busenitz, L. W., \& Lau, C.-M. (1996). A Cross-Cultural Cognitive Model of New Venture Creation. Entrepreneurship Theory and Practice, 20(4), 25-40.

Carland, J. W., Hoy, F., Boulton, W. R., \& Carland, J. A. C. (1984). Differentiating Entrepreneurs from Small Business Owners: A Conceptualization. The Academy of Management Review, 9(2), 354-359.

Carsrud, A., Brännback, M., Elfving, J., \& Brandt, K. (2009). Motivations: The Entrepreneurial Mind and Behavior. In A. L. Carsrud \& M. Brännback (Eds.), Understanding the Entrepreneurial Mind: Opening the Black Box (pp. 141-165). Springer.

Chandler, G. N., Honig, B., \& Wiklund, J. (2005). Antecedents, moderators, and performance consequences of membership change in new venture teams. Journal of Business Venturing, 20(5), 705-725.

Chowdhury, S. (2005). Demographic diversity for building an effective entrepreneurial team: Is it important? Journal of Business Venturing, 20(6), 727-746.

Colombo, M. G., \& Grilli, L. (2010). On growth drivers of high-tech start-ups: Exploring the role of founders' human capital and venture capital. Journal of Business Venturing, 25(6), 610-626.

Cooney, T. M. (2005). Editorial: What is an Entrepreneurial Team? International Small Business Journal, 23(3), 226-235.

Cooper, A. C., Woo, C. Y., \& Dunkelberg, W. C. (1989). Entrepreneurship and the initial size of firms. Journal of Business Venturing, 4(5), 317-332.

Covin, J. G., \& Miles, M. P. (1999). Corporate Entrepreneurship and the Pursuit of Competitive Advantage. Entrepreneurship Theory and Practice, 23(3), 47-63.

Cullen, J. B., Johnson, J. L., \& Parboteeah, K. P. (2014). National Rates of Opportunity Entrepreneurship Activity: Insights from Institutional Anomie Theory. Entrepreneurship Theory and Practice, 38(4), 775-806.

Davidsson, P., \& Honig, B. (2003). The role of social and human capital among nascent entrepreneurs. Journal of Business Venturing, 18(3), 301-331.

Davis, A. E., \& Shaver, K. G. (2012). Understanding Gendered Variations in Business Growth Intentions across the Life Course. Entrepreneurship Theory and Practice, 36(3), 495-512. 
De Clercq, D., Lim, D. S. K., \& Oh, C. H. (2013). Individual-Level Resources and New Business Activity: The Contingent Role of Institutional Context. Entrepreneurship Theory and Practice, 37(2), 303-330.

Donaldson, C. (2021). Culture in the entrepreneurial ecosystem: A conceptual framing. International Entrepreneurship and Management Journal, 17(1), 289-319.

Fis, A.M. \& Cetindamar, D. (2021). Unlocking the Relationship between Corporate Entrepreneurship and Firm Performance. Entrepreneurship Research Journal, 11(1)

Fuentelsaz, L., González, C., Maícas, J. P., \& Montero, J. (2015). How Different Formal Institutions Affect Opportunity and Necessity Entrepreneurship. BRQ Business Research Quarterly, 18(4), 246-258.

Fuentelsaz, L., Maicas, J. P., \& Montero, J. (2018). Entrepreneurs and innovation: The contingent role of institutional factors. International Small Business Journal, 36(6), 686-711.

Gartner, W. B. (1985). A Conceptual Framework for Describing the Phenomenon of New Venture Creation. Academy of Management Review, 10(4), 696-706.

Gartner, W. B., Carter, N. M., \& Reynolds, P. D. (2004). Business Start-up Activities. In Handbook of Entrepreneurial Dynamics: The Process of Business Creation (pp. 285-298). SAGE Publications.

Grossman, E. B., Yli-Renko, H., \& Janakiraman, R. (2012). Resource Search, Interpersonal Similarity, and Network Tie Valuation in Nascent Entrepreneurs' Emerging Networks. Journal of Management, 38(6), 1760-1787.

Guerrero, M., \& Peña-Legazkue, I. (2013). The effect of intrapreneurial experience on corporate venturing: Evidence from developed economies. International Entrepreneurship and Management Journal, 9(3), 397-416.

Guth, W. D., \& Ginsberg, A. (1990). Guest Editors' Introduction: Corporate Entrepreneurship. Strategic Management Journal, 11, 5-15.

Harper, D. A. (2008). Towards a theory of entrepreneurial teams. Journal of Business Venturing, 23(6), 613-626.

Hart, D. M. (2014). Founder nativity, founding team formation, and firm performance in the U.S. hightech sector. International Entrepreneurship and Management Journal, 10(1), 1-22.

Hayes, A. F. (2018). Introduction to Mediation, Moderation, and Conditional Process Analysis: A Regression-Based Approach (2nd ed.). Guilford Press.

Hayes, A. F., \& Rockwood, N. J. (2020). Conditional process analysis: Concepts, computation, and advances in the modeling of the contingencies of mechanisms. American Behavioral Scientist, 64(1), 19-54. https://doi.org/10.1177/0002764219859633

Hayton, J. C. (2005). Promoting corporate entrepreneurship through human resource management practices: A review of empirical research. Human Resource Management Review, 15(1), 21-41.

Hayton, J. C., George, G., \& Zahra, S. A. (2002). National Culture and Entrepreneurship: A Review of Behavioral Research. Entrepreneurship Theory and Practice, 26(4), 33-52.

Held, L., Herrmann, A. M., \& van Mossel, A. (2018). Team formation processes in new ventures. Small Business Economics, 51(2), 441-464.

Heritage Foundation. (2020). Index of Economic Freedom. https://www.heritage.org/index

Hofstede, G. (1984). Culture's Consequences: International Differences in Work-Related Values. SAGE.

Hofstede, G. (2001). Culture's Consequences: Comparing Values, Behaviors. SAGE Publications.

Hsu, B. X., \& Chen, Y. M. (2021). Why university matters: The impact of university resources on foreign workers' human and social capital accumulation. International Entrepreneurship and Management Journal, 17(1), 45-61.

Huang, V. Z., Nandialath, A., Kassim Alsayaghi, A., \& Esra Karadeniz, E. (2013). Socio-demographic factors and network configuration among MENA entrepreneurs. International Journal of Emerging Markets, 8(3), 258-281.

Hundt, C., \& Sternberg, R. (2016). Explaining new firm creation in Europe from a spatial and time perspective: A multilevel analysis based upon data of individuals, regions and countries. Papers in Regional Science, 95(2), 223-257.

Imai, K., Keele, L., \& Tingley, D. (2010). A general approach to causal mediation analysis. Psychological Methods, 15(4), 309-334.

Kacperczyk, A. J. (2012). Social Influence and Entrepreneurship: The Effect of University Peers on Entrepreneurial Entry. Organization Science, 24(3), 664-683.

Kacperczyk, A., \& Marx, M. (2016). Revisiting the Small-Firm Effect on Entrepreneurship: Evidence from Firm Dissolutions. Organization Science, 27(4), 893-910. 
Kamm, J. B., Shuman, J. C., Seeger, J. A., \& Nurick, A. J. (1990). Entrepreneurial Teams in New Venture Creation: A Research Agenda. Entrepreneurship Theory and Practice, 14(4), 7-17.

Kamm, J. B., \& Nurick, A. J. (1993). The Stages of Team Venture Formation: A Decision-making Model. Entrepreneurship Theory and Practice, 17(2), 17-27.

Kato, M., Okamuro, H., \& Honjo, Y. (2015). Does Founders' Human Capital Matter for Innovation? Evidence from Japanese Start-ups. Journal of Small Business Management, 53(1), 114-128.

Kibler, E., Salmivaara, V., Stenholm, P., \& Terjesen, S. (2018). The evaluative legitimacy of social entrepreneurship in capitalist welfare systems. Journal of World Business, 53(6), 944-957.

Klotz, A. C., Hmieleski, K. M., Bradley, B. H., \& Busenitz, L. W. (2014). New Venture Teams: A Review of the Literature and Roadmap for Future Research. Journal of Management, 40(1), 226-255.

Lazar, M., Miron-Spektor, E., Agarwal, R., Erez, M., Goldfarb, B., \& Chen, G. (2020). Entrepreneurial team formation. Academy of Management Annals, 14(1), 29-59.

Li, Y., \& Zahra, S. A. (2012). Formal institutions, culture, and venture capital activity: A cross-country analysis. Journal of Business Venturing, 27(1), 95-111.

Meoli, A., Fini, R., Sobrero, M., \& Wiklund, J. (2020). How entrepreneurial intentions influence entrepreneurial career choices: The moderating influence of social context. Journal of Business Venturing, 35(3), 105982.

Mindruta, D. (2013). Value creation in university-firm research collaborations: A matching approach. Strategic Management Journal, 34(6), 644-665.

Morales, C., Holtschlag, C., Masuda, A. D., \& Marquina, P. (2019). In which cultural contexts do individual values explain entrepreneurship? An integrative values framework using Schwartz's theories. International Small Business Journal, 37(3), 241-267.

Morris, M. H., Miyasaki, N. N., Watters, C. E., \& Coombes, S. M. (2006). The Dilemma of Growth: Understanding Venture Size Choices of Women Entrepreneurs. Journal of Small Business Management, 44(2), 221-244.

Mueller, S. L., \& Thomas, A. S. (2001). Culture and entrepreneurial potential: A nine country study of locus of control and innovativeness. Journal of Business Venturing, 16(1), 51-75.

Peterson, R. (1988). Understanding and Encouraging Entrepreneurship Internationally. Journal of Small Business Management, 26(2), 1.

Reynolds, P., Bosma, N., Autio, E., Hunt, S., De Bono, N., Servais, I., Lopez-Garcia, P., \& Chin, N. (2005). Global Entrepreneurship Monitor: Data Collection Design and Implementation 1998-2003. Small Business Economics, 24(3), 205-231.

Reynolds, P. D. (2011). Informal and Early Formal Financial Support in the Business Creation Process: Exploration with PSED II Data Set. Journal of Small Business Management, 49(1), 27-54.

Ruef, M. (2010). The Entrepreneurial Group: Social Identities, Relations, and Collective Action. Princeton University Press.

Ruef, M., Aldrich, H. E., \& Carter, N. M. (2003). The Structure of Founding Teams: Homophily, Strong Ties, and Isolation among U.S. Entrepreneurs. American Sociological Review, 68(2), 195-222.

Schjoedt, L., \& Kraus, S. (2009). Entrepreneurial teams: Definition and performance factors. Management Research News, 32(6), 513-524.

Shane, S. (2000). Prior Knowledge and the Discovery of Entrepreneurial Opportunities. Organization Science, 11(4), 448-469.

Shane, S. (2009). Why encouraging more people to become entrepreneurs is bad public policy? Small Business Economics, 33(2), 141-149.

Shane, S., \& Venkataraman, S. (2000). The Promise of Entrepreneurship as a Field of Research. The Academy of Management Review, 25(1), 217-226.

Snijders, T. A. B., \& Bosker, R. J. (2012). Multilevel analysis: An introduction to basic and advanced multilevel modeling (2nd ed). Sage.

Steensma, H. K., Marino, L., \& Weaver, K. M. (2000). Attitudes Toward Cooperative Strategies: A CrossCultural Analysis of Entrepreneurs. Journal of International Business Studies, 31(4), 591-609.

Sternberg, R., \& Wennekers, S. (2005). Determinants and Effects of New Business Creation Using Global Entrepreneurship Monitor Data. Small Business Economics, 24(3), 193-203.

Tabares, A., Chandra, Y., Alvarez, C., \& Escobar-Sierra, M. (2021). Opportunity-related behaviors in international entrepreneurship research: A multilevel analysis of antecedents, processes, and outcomes. International Entrepreneurship and Management Journal, 17(1), 321-368.

Taylor, M. Z., \& Wilson, S. (2012). Does culture still matter? The effects of individualism on national innovation rates. Journal of Business Venturing, 27(2), 234-247. 
Thomas, A. S., \& Mueller, S. L. (2000). A Case for Comparative Entrepreneurship: Assessing the Relevance of Culture. Journal of International Business Studies, 31(2), 287-301.

Tingley, D., Yamamoto, T., Hirose, K., Keele, L., \& Imai, K. (2014). mediation: R Package for Causal Mediation Analysis. Journal of Statistical Software, 59(1), 1-38.

Turro, A., Alvarez, C., \& Urbano, D. (2016). Intrapreneurship in the Spanish context: A regional analysis. Entrepreneurship \& Regional Development, 28(5-6), 380-402.

Triandis, H. C. (1993). Collectivism and Individualism as Cultural Syndromes. Cross-Cultural Research, 27(3-4), 155-180.

Ucbasaran, D., Lockett, A., Wright, M., \& Westhead, P. (2003). Entrepreneurial Founder Teams: Factors Associated with Member Entry and Exit. Entrepreneurship Theory and Practice, 28(2), 107-128.

Van der Zwan, P., Thurik, R., Verheul, I., \& Hessels, J. (2016). Factors influencing the entrepreneurial engagement of opportunity and necessity entrepreneurs. Eurasian Business Review, 6(3), 273-295.

Wasserman, N. (2012). The Founder's Dilemmas: Anticipating and Avoiding the Pitfalls That Can Sink a Startup. Princeton University Press.

Wennberg, K., Wiklund, J., \& Wright, M. (2011). The effectiveness of university knowledge spillovers: Performance differences between university spinoffs and corporate spinoffs. Research Policy, 40(8), 1128-1143.

World Bank. (2020). World Development Indicators 2020. https://databank.worldbank.org

Yusuf, J. (2012). Why do nascent entrepreneurs use external assistance programs?. Journal of Entrepreneurship and Public Policy, 1(2), 166-182.

Wennekers, S., van Stel, A., Thurik, R., \& Reynolds, P. (2005). Nascent Entrepreneurship and the Level of Economic Development. Small Business Economics, 24(3), 293-309.

Publisher's Note Springer Nature remains neutral with regard to jurisdictional claims in published maps and institutional affiliations. 